\title{
Study on Multi-Degree of Freedom Dynamic Vibration Absorber of the Carbody of High-Speed Trains
}

\section{Yu SUN}

Tongji University https://orcid.org/0000-0002-3023-4911

Jinsong Zhou ( $\square$ jinsong.zhou@tongji.edu.cn )

Institute of Rail Transit, Tongji University

Dao Gong

Institute of Rail Transit, Tongji University

Yuanjin Ji

Tongji University

\section{Original Article}

Keywords: High-speed trains, Multi-DOF dynamic vibration absorber, High static and low dynamic stiffness mount, under-chassis device, parameter optimization.

Posted Date: May 18th, 2021

DOI: https://doi.org/10.21203/rs.3.rs-516966/v1

License: (c) (i) This work is licensed under a Creative Commons Attribution 4.0 International License. Read Full License 


\title{
Study on Multi-Degree of Freedom Dynamic Vibration Absorber of the carbody of High-speed Trains
}

\author{
Yu Sun ${ }^{\mathrm{a}, \mathrm{b}}$, Jinsong Zhou ${ }^{\mathrm{b}, *}$, Dao Gong ${ }^{\mathrm{b}}$, Yuanjin Ji $\mathrm{ji}^{\mathrm{a}, \mathrm{b}}$ \\ a Postdoctoral Station of Mechanical Engineering, Tongji University, Shanghai 201804, PR China \\ ${ }^{\mathrm{b}}$ Institute of Rail Transit, Tongji University, Shanghai 201804, PR China
}

Abstract: To absorb the vibration of the carbody of the high-speed train in multiple degrees of freedom, a multi-degree of freedom dynamic vibration absorber (MDOF DVA) is proposed. Installed under the carbody, the natural vibration frequency of the MDOF DVA from each DOF can be designed as a DVA for each single degree of freedom of the carbody. Hence, a 12-DOF model including the main vibration system and a MDOF DVA is established, and the principle of MultiDOF dynamic vibration absorption is analyzed by combining the design method of single DVA and genetic algorithm. Based on a high-speed train dynamics model including an under-carbody MDOF DVA, the vibration control effect on each DOF of the MDOF DVA is analyzed by the virtual excitation method. Moreover, a high static and low dynamic stiffness (HSLDS) mount is proposed based on a cam-roller-spring mechanism for the installation of the MDOF DVA due to the requirement of the low vertical dynamic stiffness. From the dynamic simulation of a non-linear model in time-domain, the vibration control performance of the MDOF DVA installed with nonlinear HSLDS mount on the carbody is analyzed. The results show that the MDOF DVA can absorb the vibration of the carbody in multiple degrees of freedom effectively, and improve the running ride quality of the vehicle.

Key words: High-speed trains; Multi-DOF dynamic vibration absorber; High static and low dynamic stiffness mount; under-chassis device; parameter optimization.

\section{Introduction}

A gigantic source of discomfort for passengers comes from the vibration of the carbody of high-speed trains. Many researches for vibration control of carbody is mainly dedicated to improving its ride quality, from which it is expected to select an optimal set of suspension parameters or design an equipment for vibration control. As a classical passive control element, dynamic vibration absorber (DVA) [1-3] is widely used in bridge, aviation and other engineering fields. In recent researches, the control mechanism of DVA is used to suppress the vibration of the rail vehicle system. Gong et al. [4] proposed to design an underframe device as a DVA of the vehicle body to suppress the elastic vertical bouncing vibration of the carbody. By the same principle, a method of multi-mode vibration control for carbody by using the on board and suspended devices as DVAs was studied [5]. Takahiro et al. [6] designed the longitudinal vibration of the frame as a DVA for the vertical bending vibration of the carbody. And it is proved that the vibration of the carbody is reduced effectively by numerical simulation analysis and experimental research. Shi et al [7]. modeled the carbody as an Euler-Bernoulli beam and apply DVA theory to restrain the elastic vibration of carbody for high-speed electric multiple unit. The advantage of elastic vibration suppression method was verified by a laboratory test on the full-scale test rig.

\footnotetext{
* Corresponding author.

E-mail address: jinsong.zhou@tongji.edu.cn
} 
Previous researches on the carbody vibration control with DVA concentrate on the elastic vibration rather than the rigid vibration, because of the limitation from the stiffness of the mounting components. The DVA for the elastic the carbody vibration control is usually aimed at a frequency band around $10 \mathrm{~Hz}$, while the rigid one is much lower than that, with a general figure of $1 \mathrm{~Hz}$. To achieve such a low frequency, it is supposed to install the DVA with extremely low dynamic stiffness components. But the traditional linear elastic element, the static deflection is too large to be implemented. And this contradiction can be solved by a nonlinear component with high static stiffness and low dynamic stiffness (HSLDS). The HSLDS was first proposed more than 30 years ago under the name of quasi-zero stiffness (QZS) [8]. Due to its complex mechanical characteristics, a single component can hardly obtain equivalent mechanical characteristics. Instead, a negative stiffness mechanism is used in parallel with a positive stiffness elasticity, so that it exhibits HSLDS characteristics near the equilibrium position. According to the form of negative stiffness structure, HSLDS mounts can be achieved by using three parallel springs [9], disc springs [10], or cam-rollerspring [11], etc. Thanh [12] proposed to apply HSLDS to car seat suspension, which can effectively widen the vibration isolation frequency band and then achieve low frequency vibration isolation. Lee [13] proposed to apply the negative stiffness for vibration isolation of high-speed vehicles to improve ride comfort by changing structure of the bogie frame. SUN [14] proposed to connect highspeed carbody to under-chassis equipment by HSLDS components to reduce the negative impact of the excitation source equipment on the vibration of the cardbody.

Combining DVA with HSLDS mounts, Ref. [15] proposed a two-degree-of-freedom DVA under high-speed carbody to absorb the bouncing and pitching vibration, and designed a HSLDS element to install the low-frequency 2DOF DVA. Herein it proposed a multi-degree of freedom DVA (MDOF DVA) to absorb multiple degrees of freedom of vibration of the main vibration system simultaneously with one object. The main content of this paper is organized as follows: in section 2, a 12-DOF model based on two objects is built, and the design method of DVA is combined with genetic algorithm to analyze the principle of MDOF DVA. In Section 3, a high-speed vehicle dynamic model is established, and the vibration absorption performance of MDOF DVA on the rigid vibration of the carbody is analyzed by virtual excitation method [16]. In order to meet the low dynamic stiffness requirements of the MDOF DVA, a HSLDS mount is designed based on the camroller-spring mechanism in section 4 . A time-domain integral simulation analysis model with the consideration of the nonlinear characteristics of the HSLDS mount is established in Section 5 by MATLAB/SIMULINK software, and a simulation experiment is utilized to analyze the vibration control performance of MDOF DVA on the high-speed carbody. Conclusions are attached in section 6 .

\section{Mechanism of MDOF DVA based on acceleration}

\subsection{Modelling}

A typical DVA consists of assistant mass, springs, and dampers. In a system with DVA, the assistant mass vibrates along with the vibration of main system. The force applied on the main system is opposite to the external excitation force due to the dynamic effect of the DVA. Thereby, the vibration of the main system is suppressed because the combined force applied on the main system is reduced.

The schematic diagram of a MDOF DVA is shown in Fig. 1. The lower object is the main vibration system, and the upper object is the assistant mass as a DVA. Both the main system and the assistant mass are regarded as 6-DOF bodies. The assistant mass is connected to the main system 
through four points by elastic mounts. Four points under the main system are installed at the earth coordinates by elastic elements. Based on the structural model, mathematical equations are established to analyze the vibration absorption effect of the DVA on the main system.

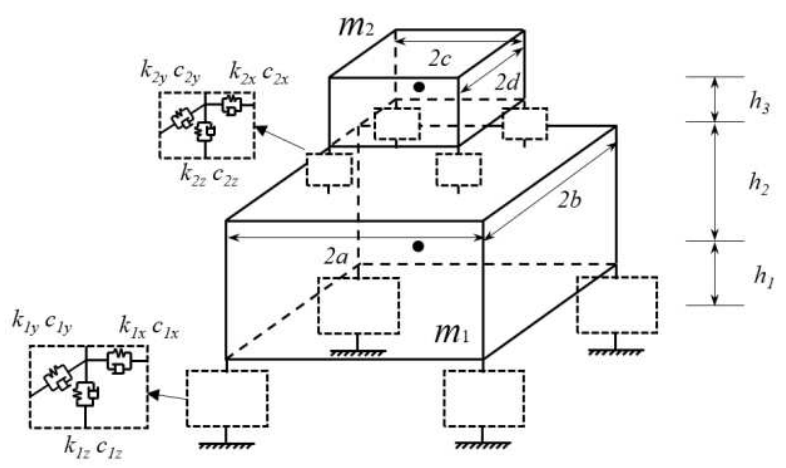

Fig. 1 Schematic diagram of a MDOF DVA

By using the matrix assembly method[16], the mathematical differential equations of the multiDOF DVA structural model can be obtained as follows:

$$
\begin{aligned}
& m_{1} \ddot{x}_{1}+4\left(c_{1 x}+c_{2 x}\right) \dot{x}_{1}+4\left(k_{1 x}+k_{2 x}\right) x_{1}-4 c_{2 x} \dot{x}_{2}-4 k_{2 x} x_{2} \\
& +4\left(c_{1 x} h_{1}-c_{2 x} h_{2}\right) \dot{\theta}_{1}+4\left(h_{1} k_{1 x}-h_{2} k_{2 x}\right) \theta_{1}-4 c_{2 x} h_{3} \dot{\theta}_{2}-4 h_{3} k_{2 x} \theta_{2}=0 \\
& m_{1} \ddot{y}_{1}+4\left(c_{1 y}+c_{2 y}\right) \dot{y}_{1}+4\left(k_{1 y}+k_{2 y}\right) y_{1}-4 c_{2 y} \dot{y}_{2}-4 k_{2 y} y_{2} \\
& -4\left(c_{1 y} h_{1}-c_{2 y} h_{2}\right) \dot{\varphi}_{1}-4\left(h_{1} k_{1 y}-h_{2} k_{2 y}\right) \varphi_{1}+4 c_{2 y} h_{3} \dot{\varphi}_{2}+4 h_{3} k_{2 y} \varphi_{2}=0 \\
& m_{1} \ddot{z}_{1}+4\left(c_{1 z}+c_{2 z}\right) \dot{z}_{1}+4\left(k_{1 z}+k_{2 z}\right) z_{1}-4 c_{2 z} \dot{z}_{2}-4 k_{2 z} z_{2}=0 \\
& I_{1 x} \ddot{\varphi}_{1}+4\left(b^{2} c_{1 z}+d^{2} c_{2 z}+c_{1 y} h_{1}^{2}+c_{2 y} h_{2}^{2}\right) \dot{\varphi}_{1}+4\left(b^{2} k_{1 z}+d^{2} k_{2 z}+h_{1}^{2} k_{1 y}+h_{2}^{2} k_{2 y}\right) \varphi_{1} \\
& -4\left(d^{2} c_{2 z}-c_{2 y} h_{3} h_{2}\right) \dot{\varphi}_{2}-4\left(d^{2} k_{2 z}-h_{3} h_{2} k_{2 y}\right) \varphi_{2}-4\left(c_{1 y} h_{1}-c_{2 y} h_{2}\right) \dot{y}_{1}-4\left(k_{1 y} h_{1}-k_{2 y} h_{2}\right) y_{1} \\
& -4 c_{2 y} h_{2} \dot{y}_{2}-4 k_{2 y} h_{2} y_{2}=0 \\
& I_{1 y} \ddot{\theta}_{1}+4\left(a^{2} c_{1 z}+c^{2} c_{2 z}+h_{1}^{2} c_{1 x}+h_{2}^{2} c_{2 x}\right) \dot{\theta}_{1}+4\left(a^{2} k_{1 z}+c^{2} k_{2 z}+h_{1}^{2} k_{1 x}+h_{2}^{2} k_{2 x}\right) \theta_{1} \\
& -4\left(c^{2} c_{2 z}-h_{2} h_{3} c_{2 x}\right) \dot{\theta}_{2}-4\left(c^{2} k_{2 z}-h_{2} h_{3} k_{2 x}\right) \theta_{2}+4\left(h_{1} c_{1 x}-h_{2} c_{2 x}\right) \dot{x}_{1}+4\left(h_{1} k_{1 x}-h_{2} k_{2 x}\right) x_{1} \\
& +4 h_{2} c_{2 x} \dot{x}_{2}+4 h_{2} k_{2 x} x_{2}=0 \\
& I_{1 z} \ddot{\psi}_{1}+4\left(a^{2} c_{1 y}+b^{2} c_{1 x}+c^{2} c_{2 y}+d^{2} c_{2 x}\right) \dot{\psi}_{1}+4\left(a^{2} k_{1 y}+b^{2} k_{1 x}+c^{2} k_{2 y}+d^{2} k_{2 x}\right) \psi_{1} \\
& -4\left(c^{2} c_{2 y}+d^{2} c_{2 x}\right) \dot{\psi}_{2}-4\left(c^{2} k_{2 y}+d^{2} k_{2 x}\right) \psi_{2}=0 \\
& m_{2} \dot{x}_{2}+4 c_{2 x} \dot{x}_{2}+4 k_{2 x} x_{2}-4 c_{2 x} \dot{x}_{1}-4 k_{2 x} x_{1}+4 c_{2 x} h_{2} \dot{\theta}_{1}+4 h_{2} k_{2 x} \theta_{1} \\
& +4 c_{2 x} h_{3} \dot{\theta}_{2}+4 h_{3} k_{2 x} \theta_{2}=0 \\
& m_{2} \ddot{y}_{2}+4 c_{2 y} \dot{y}_{2}+4 k_{2 y} y_{2}-4 c_{2 y} \dot{y}_{1}-4 k_{2 y} y_{1}-4 c_{2 y} h_{2} \dot{\varphi}_{1}-4 h_{2} k_{2 y} \varphi_{1}-4 c_{2 y} h_{3} \dot{\varphi}_{2}-4 h_{3} k_{2 y} \varphi_{2}=0 \\
& m_{2} \ddot{z}_{2}+4 c_{2 z} \dot{z}_{2}+4 k_{2 z} z_{2}-4 c_{2 z} \dot{z}_{1}-4 k_{2 z} z_{1}=0 \\
& I_{2 x} \ddot{\varphi}_{2}+4\left(d^{2} c_{2 z}+h_{3}^{2} c_{2 y}\right) \dot{\varphi}_{2}+4\left(d^{2} k_{2 z}+h_{3}^{2} k_{2 y}\right) \varphi_{2}-4\left(d^{2} c_{2 z}-h_{2} h_{3} c_{2 y}\right) \dot{\varphi}_{1}- \\
& 4\left(d^{2} k_{2 z}-h_{2} h_{3} k_{2 y}\right) \varphi_{1}+4 c_{2 y} h_{3} \dot{y}_{1}+4 k_{2 y} h_{3} y_{1}-4 c_{2 y} h_{3} \dot{y}_{2}-4 k_{2 y} h_{3} y_{2}=0 \\
& I_{2 y} \ddot{\theta}_{2}+4\left(c^{2} c_{2 z}+h_{3}^{2} c_{2 x}\right) \dot{\theta}_{2}+4\left(c^{2} k_{2 z}+h_{3}^{2} k_{2 x}\right) \theta_{2}-4\left(c^{2} c_{2 z}-h_{2} h_{3} c_{2 x}\right) \dot{\theta}_{1} \\
& -4\left(c^{2} k_{2 z}-h_{2} h_{3} k_{2 x}\right) \theta_{1}-4 h_{3} c_{2 x} \dot{x}_{1}-4 h_{3} k_{2 x} x_{1}+4 h_{3} c_{2 x} \dot{x}_{2}+4 h_{3} k_{2 x} x_{2}=0 \\
& I_{2 z} \ddot{\psi}_{2}+4\left(c^{2} c_{2 y}+d^{2} c_{2 x}\right) \dot{\psi}_{2}+4\left(c^{2} k_{2 y}+d^{2} k_{2 x}\right) \psi_{2}-4\left(c^{2} c_{2 y}+d^{2} c_{2 x}\right) \dot{\psi}_{1}-4\left(c^{2} k_{2 y}+d^{2} k_{2 x}\right) \psi_{1}=0
\end{aligned}
$$

The symbols, meanings and default values involved in the equations are shown in Appendix 1. By writing the above equation into a compact form, the following equation is obtained: 


$$
M \ddot{X}+C \dot{X}+K X=0
$$

where $X=\left[\begin{array}{llllllllllll}x_{1} & y_{1} & z_{1} & \varphi_{1} & \theta_{1} & \psi_{1} & x_{2} & y_{2} & z_{2} & \varphi_{2} & \theta_{2} & \psi_{2}\end{array}\right]^{\mathrm{T}} . M, C$ and $K$ are the mass matrix, damping matrix and stiffness matrix of the system, respectively. With the character of the stiffness matrix $K$, the vertical motion and yaw of the system are completely decoupled from the movements in the other directions. By combing Eq.(3) and Eq. (9), the DVA of vertical motion can be obtained according to the design principle of single degree of freedom DVA[10]. By the same principle, the yaw DVA can be obtained from Eq.(6) and Eq.(12). Similarly, the remaining four degrees of freedom of the assistant system can also be designed as dynamic vibration absorber of the main system theoretically.

\subsection{Vibration shape and frequency analysis of the main system}

In order to obtain the design target frequency of the DVA, it is necessary to analyze the vibration frequency of the main system in each degree of freedom without the assist system. A 6DOF equation describing the vibration of the main system can be obtained by removing the assist system in Fig. 1. The natural vibration frequencies of the main system and the corresponding vibration shape [17] is shown in Fig. 2. From that the lateral motion (the $2^{\text {nd }}$ vibration shape) is coupled vibrates with rolling mode (the $4^{\text {th }}$ vibration shape), and the longitudinal motion (the $1^{\text {st }}$ vibration shape) is coupled vibrates with pitching mode (the $5^{\text {th }}$ vibration shape).

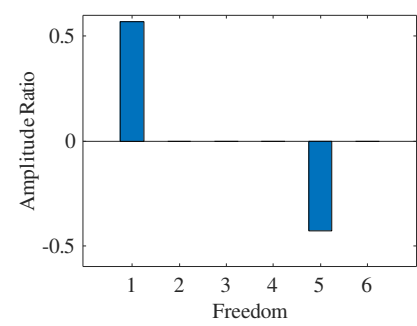

(a) longitudinal motion

$(8.60 \mathrm{~Hz})$

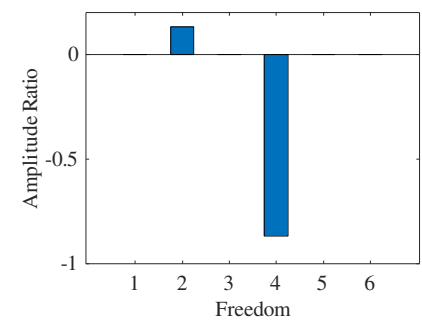

(d) rolling $(14.0 \mathrm{~Hz})$

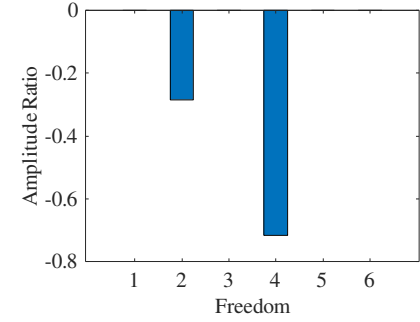

(b) lateral motion $(9.45 \mathrm{~Hz})$

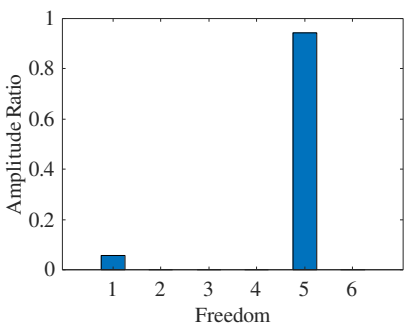

(e) pitching $(14.5 \mathrm{~Hz})$

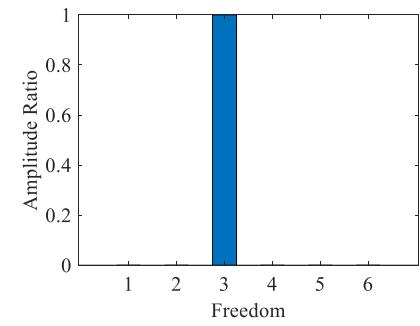

(c) bouncing $(9.93 \mathrm{~Hz})$

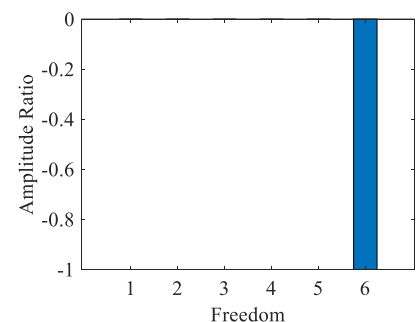

(f) yawing $(16.0 \mathrm{~Hz})$

Fig. 2 Vibration shapes of the main system

\subsection{Parameter design and optimization of MDOF DVA}

According to the design principle of single DVA based on acceleration [3], the natural vibration frequency of the MDOF DVA can be set as Eq. (14),

$$
f_{i}=\frac{1}{\sqrt{1+\mu_{i}}}
$$

where $f_{i}(i=1,2, \ldots, 6)$ is the vibration frequency of the DVA of each DOF. $\mu_{i}$ is the mass ratio or inertia ratio of the DVA to the main system. The non-damping vibration frequency of the MDOF 
DVA without the consideration of couple vibration can be expressed as Eq.(15),

$$
\left\{\begin{array}{l}
f_{\mathrm{x}}=\frac{1}{2 \pi} \sqrt{4 k_{2 \mathrm{x}} / m_{2}} \\
f_{\mathrm{y}}=\frac{1}{2 \pi} \sqrt{4 k_{2 \mathrm{y}} / m_{2}} \\
f_{\mathrm{z}}=\frac{1}{2 \pi} \sqrt{4 k_{2 \mathrm{z}} / m_{2}} \\
f_{\varphi}=\frac{1}{2 \pi} \sqrt{4\left(h_{3}^{2} k_{2 \mathrm{y}}+d^{2} k_{2 \mathrm{z}}\right) / I_{2 \mathrm{x}}} \\
f_{\theta}=\frac{1}{2 \pi} \sqrt{4\left(h_{3}^{2} k_{2 \mathrm{x}}+c^{2} k_{2 \mathrm{z}}\right) / I_{2 \mathrm{y}}} \\
f_{\psi}=\frac{1}{2 \pi} \sqrt{4\left(c^{2} k_{2 \mathrm{y}}+d^{2} k_{2 \mathrm{x}}\right) / I_{2 \mathrm{z}}}
\end{array}\right.
$$

It can be noticed that the vibration frequency of all DOFs is decided by 6 parameters, i.e. $k_{2 x}$, $k_{2 y}, k_{2 z}, h_{3}, c, d$. Therefore, a MDOF DVA that absorbs the vibrations of the main system in 6 DOFs can be designed based on the natural vibration frequency in each DOF of the assist system. However, the 6 parameters are related to each other. Some parameters may be unreasonable when the frequency is selected as design target. For example, due to space constraints, the geometric parameters $h_{3}, c$, and $d$ need to be designed within a certain range. To ensure the stability of the system, the stiffness parameters $k_{2 \mathrm{x}}, k_{2 \mathrm{y}}$ and $k_{2 \mathrm{z}}$ cannot be negative.

The acceleration frequency response function (FRF) is obtained to evaluate the vibration absorption performance of the MDOF DVA, as shown in Eq. (16).

$$
H(\omega)=\omega^{2}\left[-\omega^{2} M+j \omega C+K\right]^{-1} D \Phi
$$

where $H(\omega)$ is the acceleration FRF, $D$ is the excitation input matrix, $\Phi$ is the input position matrix, $\omega$ is the circle frequency.

The natural vibration frequency and installation parameters of the MDOF DVA are calculated by Eq. (14) and Eq. (15), as shown in Tab. 1 (a) and (b), respectively. Different from the calculated value of $13.5 \mathrm{~Hz}$, the frequency of the yaw motion is $16.5 \mathrm{~Hz}$ in Tab. 1(a), and it is because the parameters cannot satisfy the calculation results of Eq. (15) simultaneously for the rolling, yawing, and pitching frequencies (a complex result appears in the calculation). Therefore, here we choose $h_{3}$ as $0.2 \mathrm{~m}$ to calculate the values of parameters $c$ and $d$ according to the frequency requirement of rolling and pitching DVA.

\begin{tabular}{cccc} 
Tab. 1 (a) Natural vibration frequency of MDOF DVA before and after optimizatio \\
\hline \multirow{2}{*}{ Freedom } & Vibration Shape & $\begin{array}{c}\text { Natural frequency (Hz) } \\
\text { Original }\end{array}$ & optimized \\
\hline 1 & longitudinal motion & 8.60 & 10.9 \\
2 & lateral motion & 9.45 & 8.46 \\
3 & bouncing & 9.93 & 10.2 \\
4 & rolling & 14.0 & 17.2 \\
5 & pitching & 14.5 & 11.3 \\
6 & yawing & 16.0 & 13.5 \\
\hline
\end{tabular}

Tab. 1 (b) Installation parameters of MDOF DVA

\begin{tabular}{llrl}
\hline \multirow{2}{*}{ Parameter } & \multicolumn{2}{c}{ Value } & \multirow{2}{*}{ Unit } \\
& Original & optimized & \\
\hline
\end{tabular}




\begin{tabular}{cccc}
\hline$k_{2 \mathrm{x}}$ & $3.32 \times 10^{5}$ & $5.89 \times 10^{5}$ & $\mathrm{~N} / \mathrm{m}$ \\
$k_{2 \mathrm{y}}$ & $4.01 \times 10^{5}$ & $3.53 \times 10^{5}$ & $\mathrm{~N} / \mathrm{m}$ \\
$k_{2 \mathrm{z}}$ & $4.42 \times 10^{5}$ & $5.14 \times 10^{5}$ & $\mathrm{~N} / \mathrm{m}$ \\
$c$ & 1.15 & 0.966 & $\mathrm{~m}$ \\
$d$ & 0.359 & 0.739 & $\mathrm{~m}$ \\
$h_{3}$ & 0.2 & 0.2 & $\mathrm{~m}$ \\
\hline
\end{tabular}

The acceleration FRFs of each DOF of the main system is calculated by Eq. (16), as shown in Fig. 3. The damping ratio with a value of 0.06 of the MDOF DVA is selected, and the installation stiffness is determined by the natural vibration frequency. In Fig. 3, dash line stands for the acceleration FRFs of the main system without MDOF DVA, and dash-dot line is the calculation result with the original parameters of the MDOF DVA. It can be seen from that, the vibration of the longitudinal motion, bouncing, pitching and yawing has a certain but not optimal [10] effect of vibration absorption after using the original MDOF DVA. In contrast, the vibration of lateral motion and rolling has little effect, due to the unconsidered damping of the main system in the MDOF DVA parameter design and the coupling vibration between lateral motion and rolling vibration.

On the basis of the original MDOF DVA parameters, genetic algorithm is utilized to optimize the natural vibration frequency in each DOF of MDOF DVA. The maximum acceleration FRF of the main system is selected as the optimization objective function. After optimization, the natural vibration frequency and installation parameters of MDOF DVA are shown in Tab. 1(a) and (b), respectively. The optimized acceleration FRFs of the main system are shown in Fig. 3 with solid line. It illustrates that the optimal vibration absorption effects of longitudinal motion, bouncing, rolling, pitching are achieved after optimization. Compared with the results without MDOF DVA, the peak values of the 4 DOFs are declined by $37.7 \%, 40.5 \%, 42.1 \%$ and $49.4 \%$, respectively. The amplitude of lateral motion increases due to the coupling vibration with rolling. The yawing vibration is not much different from the vibration absorption effect before optimization. This is due to the limitation of the parameters, which makes it difficult to further optimize the yawing vibration. As shown in Fig. 3, MDOF DVA can simultaneously absorb vibration of multiple DOFs of the main system, but the existence of coupling vibration and the limitation of the parameters make it difficult to absorb all the vibration shapes at the same time.

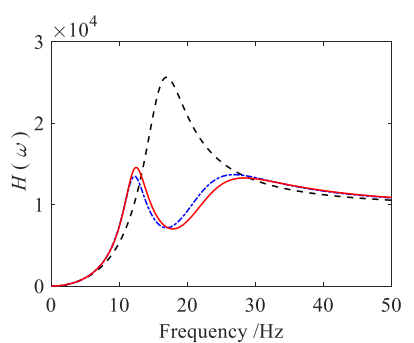

(a) longitudinal motion

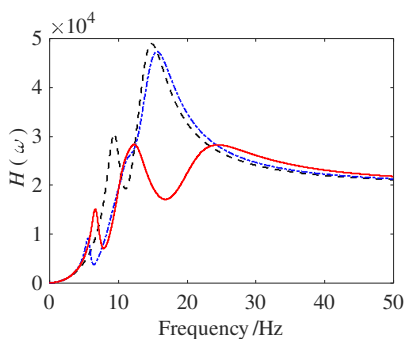

(d) rolling

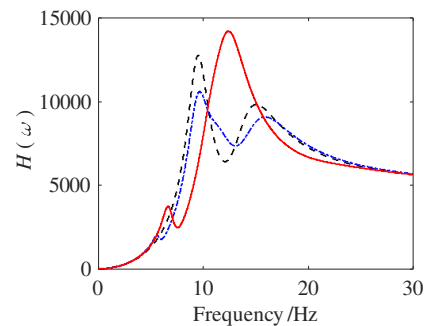

(b) lateral motion

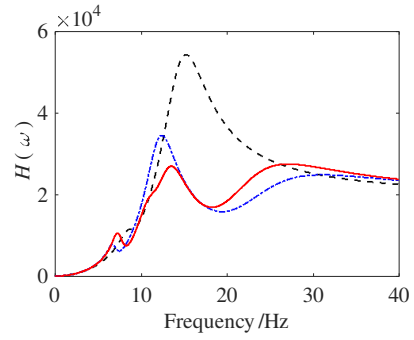

(e) pitching

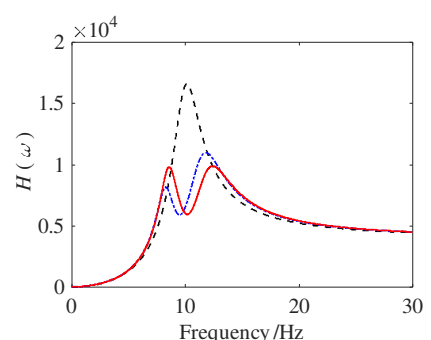

(c) bouncing

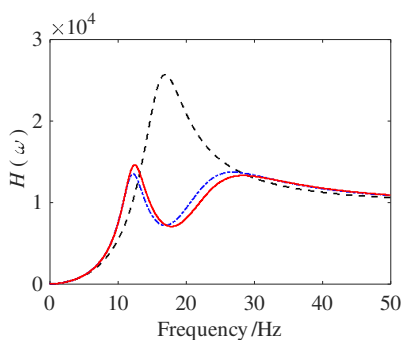

(f) yawing

Fig. 3 Acc RFR of main system. dash line: without MDOF DVA; dash-dot line: with original MDOF DVA; solid 


\section{Establishment and analysis of a high-speed train dynamic model}

\subsection{Model establishment of a high-speed train}

A high-speed train dynamic model is established to analyze the vibration suppression performance of the MDOF DVA for the carbody, the schematic diagram of which is shown in Fig. 4. The model has 28 DOFs that includes four wheelsets which consider the lateral motion and yawing $(4 \times 2 \mathrm{DOF})$, two bogies, one carbody and one MDOF DVA which consider lateral motion, bouncing, rolling, pitching, and yawing $(5 \times 4 \mathrm{DOFs})$. In the simulation analysis, it is assumed that the wheelset is close to the rail surface in the vertical direction, and the vertical irregular excitation is applied through the axle box. The lateral irregularities are imposed by the wheel-rail linear contact relationship.
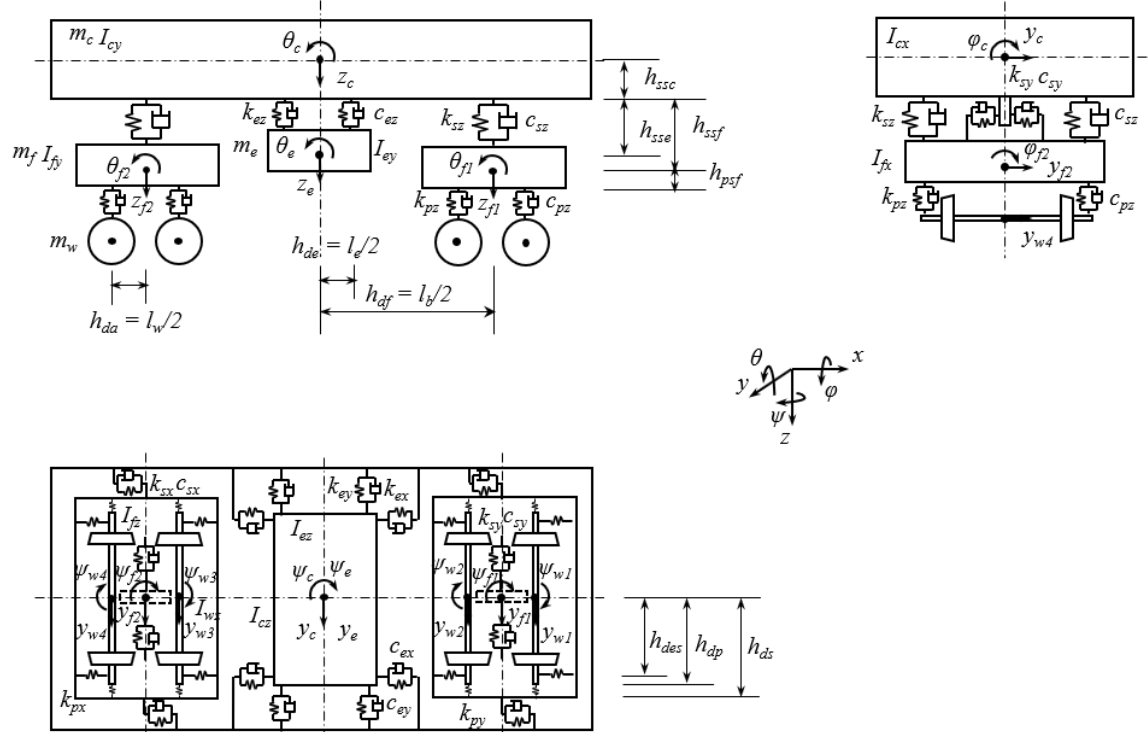

Fig. 4 Dynamic model of the high-speed train

The completed dynamic model is shown in Appendix B. The parameters and their meanings in the model are shown in Appendix Tab.2. By writing the equations into a compact form, the following equation is obtained:

$$
M_{\mathrm{t}} \ddot{Y}+C_{\mathrm{t}} \dot{Y}+K_{\mathrm{t}} Y=D_{\mathrm{w}} Y_{\mathrm{w}}
$$

where $M, C$ and $K$ are the mass matrix, damping matrix and stiffness matrix of the vehicle system, respectively. $D_{\mathrm{w}}$ stands for excitation input matrix, and $Y_{\mathrm{w}}$ stands for the track irregularity.

\subsection{Vibration shape and frequency analysis of the high-speed train}

The vibration shape of the high-speed train without DVA is obtained for the frequency design of the MDOF DVA. As shown in Fig. 4, a high-speed vehicle model with 23 DOFs is established for eigenvalue and vibration shape analysis without DVA, and the results are shown in Fig. 5. It illustrates that the lateral motion is coupled vibrates with rolling. When the two DOFs vibrate in the same direction, it is the upper core rolling, as shown in Fig. 5(c); when they vibrate in the opposite direction, it is the lower core rolling, as shown in Fig. 5(a). For the clarity of the subsequent 
description, considering the amplitude ratio of the coupled modes, the upper core rolling mode is regarded as rolling, and the lower core rolling mode is regarded as lateral motion.

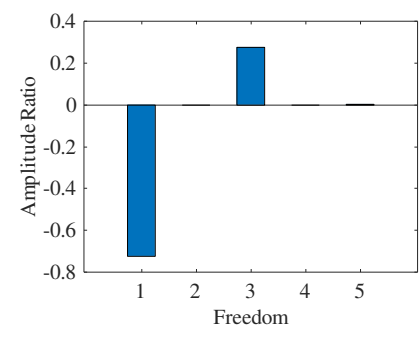

(a) lateral motion $(0.970 \mathrm{~Hz})$

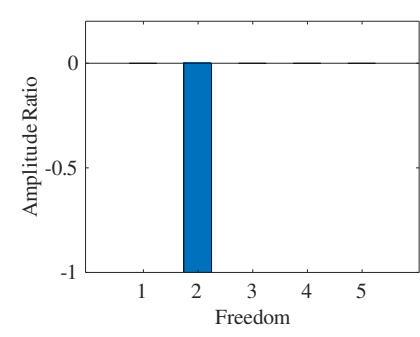

(b) bouncing $(0.958 \mathrm{~Hz})$

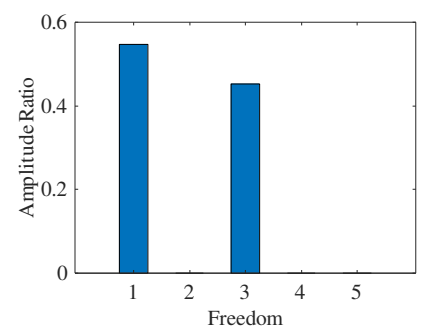

(c) rolling $(0.446 \mathrm{~Hz})$

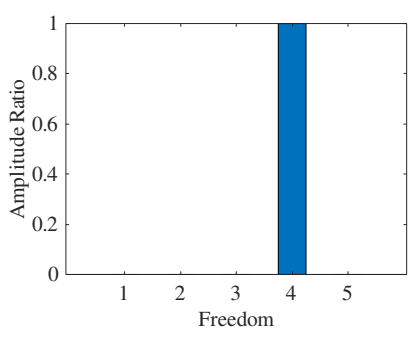

(d) pitching $(1.26 \mathrm{~Hz})$

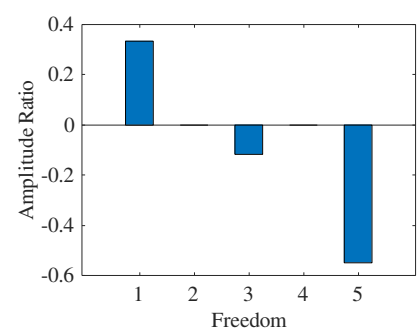

(e) yawing $(1.18 \mathrm{~Hz})$

Fig. 5 Vibration shapes of carbody

\subsection{Track irregularity input}

Track irregularity is the main excitation of the vehicle system during the operation of the highspeed train. Track irregularity excitation is input to the vehicle system through the wheelsets, and a time delay exists between each wheelset. The acceleration power spectral density (PSD) of each DOF is applied to evaluate the vibration of the carbody for investigating the vibration absorption performance of MDOF DVA. The calculate method is

$$
S=\omega^{4} \psi Y^{*} Y^{T} \psi^{T}
$$

where $(\cdot)^{*}$ stands for conjugate matrix, $(\cdot)^{T}$ stands for transpose matrix, $S$ is the acceleration PSD of each DOF of the carbody, $\psi$ is a coordinate transformation matrix. $Y$ is related to vehicle system parameters, excitation input matrix and input time delay. The expression of $Y$ is

$$
Y=\left[-\omega^{2} M_{\mathrm{t}}+j \omega C_{\mathrm{t}}+K_{\mathrm{t}}\right]^{-1} D_{\mathrm{w}} T_{\mathrm{d}} \sqrt{S_{F F}(\omega)}
$$

where $D_{\mathrm{w}}$ is the excitation input matrix, $T_{\mathrm{d}}$ is the time delay matrix, $S_{F F}(\omega)$ is the PSD of track irregularity. The high-speed track irregularity is adopted in the model [16], the vertical and lateral PSD of which are as follow:

$$
\begin{aligned}
& S_{\mathrm{v}}(\Omega)=\frac{A_{\mathrm{v}} \Omega_{\mathrm{c}}}{\left(\Omega^{2}+\Omega_{\mathrm{r}}{ }^{2}\right)\left(\Omega^{2}+\Omega_{\mathrm{c}}{ }^{2}\right)} \\
& S_{\mathrm{a}}(\Omega)=\frac{A_{\mathrm{a}} \Omega_{\mathrm{c}}}{\left(\Omega^{2}+\Omega_{\mathrm{r}}{ }^{2}\right)\left(\Omega^{2}+\Omega_{\mathrm{c}}{ }^{2}\right)}
\end{aligned}
$$

where $\Omega$ is spatial circular frequency $(\mathrm{rad} / \mathrm{m}), A_{\mathrm{v}}$ is $4.032 \times 10^{-7} \mathrm{~m} \cdot \mathrm{rad}, A_{\mathrm{a}}$ is $2.119 \times 10^{-7}$ $\mathrm{m} \cdot \mathrm{rad}, \Omega_{\mathrm{c}}$ is $0.8246 \mathrm{rad} / \mathrm{m}, \Omega_{\mathrm{r}}$ is $0.206 \mathrm{rad} / \mathrm{m}$. 


\subsection{Optimal Design of MDOF DVA for the high-speed train}

Genetic algorithm is utilized to optimize the parameters of the MDOF DVA. Due to the space limitation of chassis of the carbody, here the original parameters of the MDOF DVA do not need to be calculated based on Eq. (15) and Tab. 1, but set the parameter constraint range and use genetic algorithm to optimize the parameters of the MDOF DVA. Considering that the installation height of the DVA is usually close to the bottom of the carbody, the installation height parameter $h_{\text {see }}$ can be set to a constant value. Limited by installation space, the half of the longitudinal $l_{\mathrm{ex}}$ and lateral spans $l_{\text {ey }}$ and the installation stiffness $k_{\text {ex }}, k_{\text {ey }}, k_{\text {ez }}$ of the three directions need to set a constraint range. The optimize objective function and constraints can be set as

$$
\begin{array}{cc}
\min & g(x)=\sum_{i=1}^{5} \beta_{i} \cdot \max \left(S_{i}\right) \\
\text { s.t. } \quad & h_{\text {see }}=0.3 \\
& 2 \leq l_{\text {ex }} \leq 6 \\
0.8 & \leq l_{\text {ey }} \leq 1.6 \\
10^{4} \leq k_{\text {ex }} \leq 10^{7} \\
10^{4} \leq k_{\text {ey }} \leq 10^{7} \\
10^{4} \leq k_{\text {ey }} \leq 10^{7}
\end{array}
$$

where $S_{i}$ stands for the power spectrum density (PSD) of each DOF of the carbody, $\beta_{i}$ is weight coefficient.

The optimized natural vibration frequency and the installation parameters of the MDOF DVA can be obtained according to the optimization steps as shown in Tab. 2(a) and (b), respectively.

\begin{tabular}{ccc} 
Tab. 2(a) Natural vibration frequency of the MDOF DVA \\
\hline Freedom & Vibration shape & $\begin{array}{c}\text { Natural frequency of } \\
\text { MDOF DVA(Hz) }\end{array}$ \\
\hline 1 & lateral motion & 0.971 \\
2 & bouncing & 0.859 \\
3 & rolling & 0.545 \\
4 & pitching & 1.26 \\
5 & yawing & 1.75 \\
\hline
\end{tabular}

Tab. 2(b) Installation parameters of MDOF DVA

\begin{tabular}{ccc}
\hline Parameter & Value & Unit \\
\hline$k_{\text {ex }}$ & $2.70 \times 10^{5}$ & $\mathrm{~N} / \mathrm{m}$ \\
$k_{\text {ey }}$ & $5.58 \times 10^{4}$ & $\mathrm{~N} / \mathrm{m}$ \\
$k_{\text {ez }}$ & $4.37 \times 10^{4}$ & $\mathrm{~N} / \mathrm{m}$ \\
$l_{\text {ex }}$ & 4.77 & $\mathrm{~m}$ \\
$l_{\text {ey }}$ & 1.60 & $\mathrm{~m}$ \\
\hline
\end{tabular}

Fig.6 shows the comparison of the acceleration PSD of the carbody with the optimized MDOF DVA and without DVA. In the simulation, the installation damping ratio of the DVA is set as 0.06. Fig. 6(a) and (b) illustrate that after the MDOF DVA applied, the maximum of the lateral motion and bouncing acceleration PSD change from one to two equal values, indicating that the lateral motion and bouncing modes are achieved the optimal vibration absorption. The maximum of the lateral motion decreases from $0.045\left(\mathrm{~m} \cdot \mathrm{s}^{-2}\right)^{2} \cdot \mathrm{Hz}^{-1}$ to $0.0035\left(\mathrm{~m} \cdot \mathrm{s}^{-2}\right)^{2} \cdot \mathrm{Hz}^{-1}$, with a reduction of 92.2\%. The maximum of the bouncing mode decreases from $0.041\left(\mathrm{~m} \cdot \mathrm{s}^{-2}\right)^{2} \cdot \mathrm{Hz}^{-1}$ to $0.0063\left(\mathrm{~m} \cdot \mathrm{s}^{-}\right.$ $\left.{ }^{2}\right)^{2} \cdot \mathrm{Hz}^{-1}$, with a reduction of $84.6 \%$. It can be seen from Fig. 6(c) that the rolling vibration mode 
has a certain vibration absorption effect, but it is not optimal. It lies a cause that the rolling vibration is coupled with lateral motion, which makes it difficult to optimize both simultaneously. Fig. 6(d) demonstrates that the pitching vibration is well suppressed. Fig. 6(e) indicates that the yawing mode has no obvious vibration absorption effect, because it is difficult to design the natural frequency of the yawing mode to the optimal vibration absorbing due to the limitation of the parameter constraint range. All in Fig. 6 show that the MDOF DVA can absorb multiple vibration modes of the carbody at the same time, and some of them can achieve optimal vibration absorption. However, the limitation of parameter constraint range and coupling vibration makes it impossible to design all vibration modes at the same time as the optimal DVA of the carbody.

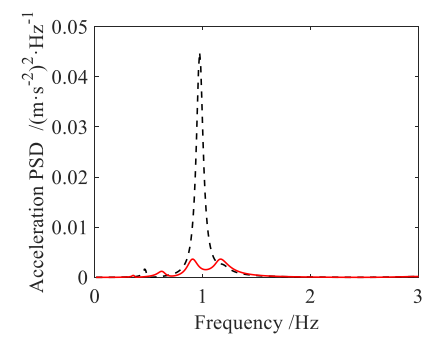

(a) lateral motion

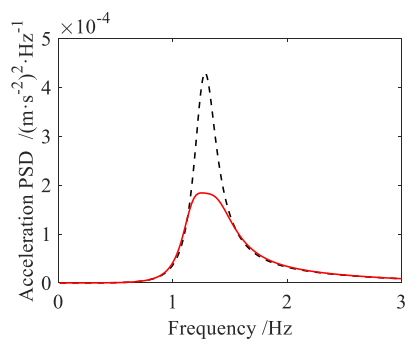

(d) pitching

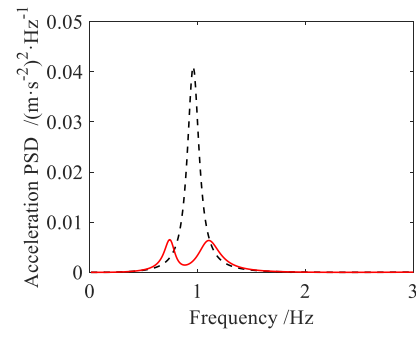

(b) bouncing

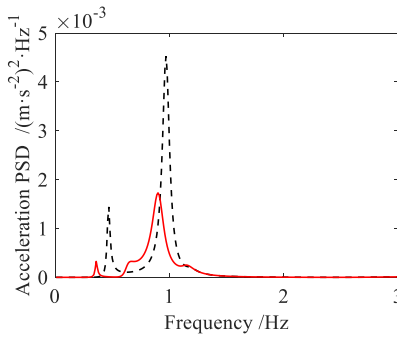

(c) rolling

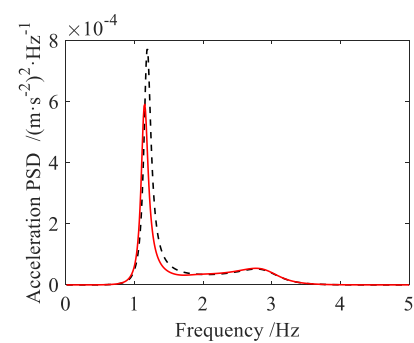

(e) yawing

Fig. 6 PSD of each DOF of the carbody. dash line: without MDOF DVA; solid line: with optimized MDOF DVA.

\section{Design of high static and low dynamic stiffness mounts}

With linear elastic isolators as the installation mounts of the MDOF DVA, the relationships of parameters of a DVA is written as Eq.(21).

$$
f_{\mathrm{d}}=\frac{1}{2 \pi} \sqrt{\frac{k_{\mathrm{z}}}{m}}, \quad \delta_{\mathrm{st}}=\frac{m g}{n k_{\mathrm{z}}}=\frac{g}{\left(2 \pi f_{\mathrm{z}}\right)^{2}}
$$

where $\mathrm{m}, k_{\mathrm{z}}, f_{\mathrm{z}}$ and $\delta_{\mathrm{st}}$ is mass, vertical installation stiffness, installation frequency and static deflection respectively, $n$ is the mounting number, which is set as 4 in this research. Eq. (21) shows that the vertical installation frequency directly determines the vertical stiffness and the static deflection. The static deflection would be extremely large if the vertical installation frequency is relatively low. According to the main vertical vibration frequency of the MDOF DVA with a value of $0.859 \mathrm{~Hz}$, the static deflection is $0.337 \mathrm{~m}$ with the linear elastic isolators. It is obviously that such a large static deflection is difficult to apply in engineering.

Hence, a high static and low dynamic (HSLDS) mount based on a cam-roller-spring mechanism is proposed. The schematic figure of the HSLDS mount is shown in Fig. 7. It is composed of a negative stiffness structure and a positive stiffness spring. The negative stiffness structure is composed by roller guide support, lateral springs, and rollers. The vertical dynamic stiffness of the HSLDS mount is given by the sum of the dynamic stiffness of the negative stiffness 
structure and the vertical spring. In addition, a height adjuster is set to arrange that the midpoint of the curved surface is in contact with the roller when the isolated object is placed in equilibrium. Different from the design of a QZS isolator in Ref. [14], this type of mount is intended for a HSLDS mount with low positive stiffness near the equilibrium position in this research.

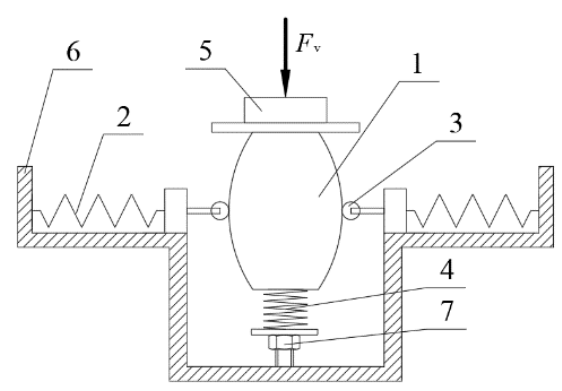

Fig. 7. Schematic design of the HSLDS mount based on target force curve (1-roller guide support, 2- lateral spring, 3-roller, 4-vertical spring, 5- isolated object, 6-fitting seat, 7-height adjuster)

The left and right guides are assumed to be symmetrical, and the force analysis of the left guide is used as an example, as shown as Fig. 8. This produces a negative stiffness in the vertical direction when the roller guide surface is convex, as shown in Fig. 8(a). In this case, when the isolated object moves upwards, the vertical component of the force exerted by the rollers is also upward, which corresponds to a negative stiffness.

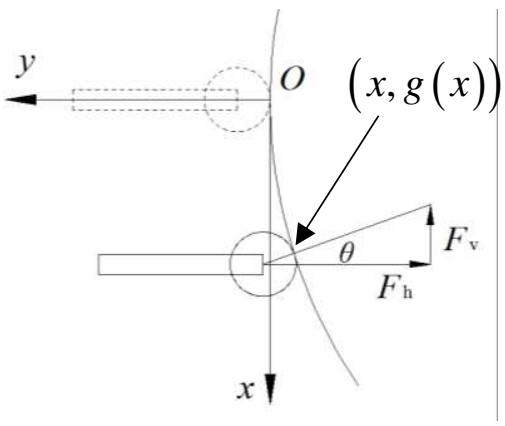

(a) Force schematic (convex)

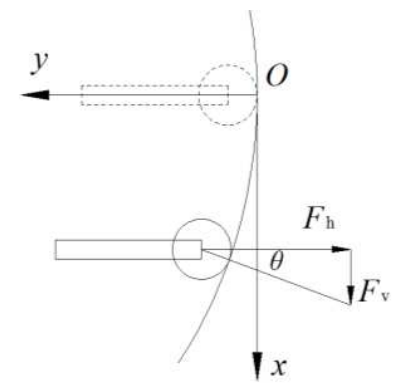

(b) Force schematic (concave)

Fig. 8. Force schematic of the HSLDS mount

The shape of the guide surface is defined by the function $y=g(x)$. It can be assumed that the effect of the roller radius on the system is negligible. As shown in Fig. 8 (a), the contact point is $(x$, $g(x)$ ) when the deflection of the isolated object from the equilibrium position is $x$ ( $g$ is negative in Fig. 8(a)). The gradient at the contact point is $g^{\prime}(x)$, which is equal to $\tan \theta$. The spring deformation can be expressed as $\Delta l+g(x)$, where $\Delta l$ is the initial pre-deformation of the lateral springs. Based on the force analysis, the force of the mount in the vertical direction can be expressed as

$$
f(x)=k_{\mathrm{v}} x+k_{\mathrm{h}}(\Delta l+g(x)) g^{\prime}(x)
$$

where $g^{\prime}(x)=\frac{\mathrm{d} g}{\mathrm{~d} x}, k_{\mathrm{v}}$ is the stiffness of the vertical spring, $k_{\mathrm{h}} / 2$ is the stiffness of the lateral spring for one side. Rearranging Eq. (24) and integrating both sides, it can be obtaines as follow,

$$
\int f(x) \mathrm{d} x=k_{\mathrm{h}} \Delta l g(x)+\frac{1}{2} k_{\mathrm{h}} g(x)^{2}+\frac{1}{2} k_{\mathrm{v}} x^{2}+C
$$


where $C$ is a constant. According to the desired equilibrium condition, the boundary conditions of Eq. (25) are $f(0)=g(0)=0$ and $C=0$. For a specific target force curve, the corresponding roller slide curve can be obtained by numerical calculation. Eq. (25) can be regarded as a quadratic polynomial equation in $g(x)$, and the solution can be obtained as

$$
g(x)=-\Delta l+\sqrt{\Delta l^{2}-\left(\frac{k_{\mathrm{v}}}{k_{\mathrm{h}}} x^{2}-\frac{2}{k_{\mathrm{h}}} \int f(x) d x\right)}
$$

It can be verified that the same result can be acquired according to force analysis of Fig. 8(b).

According to the installation parameters of the optimized MDOF DVA in Tab. 2, the vertical stiffness of which is $4.37 \times 10^{4} \mathrm{~N} / \mathrm{m}$. In order to obtain a component with a high static stiffness while the dynamic stiffness is $k_{\text {ez }}$ near the equilibrium position, the target force curve can be set as

$$
F(x)=k_{\mathrm{ez}} x+p k_{\mathrm{v}} x^{3}
$$

By differentiating Eq.(27), the stiffness of the HSLDS mount can be obtained as

$$
K(x)=k_{\mathrm{ex}}+3 p k_{\mathrm{v}} x^{2}
$$

By assuming the static deflection as $\delta_{\text {st }}$, and set $p=\delta_{\text {st }}{ }^{-2}$, the following equation can be obtained when the displacement of the suspension object is equal to its static deflection:

$$
k_{\mathrm{v}}=\frac{m g}{4 \delta_{\mathrm{st}}}-k_{\mathrm{ez}}
$$

By setting $\delta_{\text {st }}=0.03 \mathrm{~m}$, the mechanical and stiffness characteristics of the HSLDS mount is obtained as Fig. 9(a) and (b), respectively. It can be seen from Fig. 9(a) that when the displacement is $0.03 \mathrm{~m}$, the restoring force of the HSLDS mount is $m g /\left(4 k_{\mathrm{ez}}\right)$. Fig. 9(b) illustrates that the stiffness of the HSLDS mount is $k_{\text {ez }}$ at the equilibrium position. The roller guide curves of the HSLDS mount obtained according to Eq. (26) for $\Delta l=0.1 \mathrm{~m}, k_{\mathrm{h}}=k_{\mathrm{v}}$, is shown in Fig. 9(c). It can be found that the use of HSLDS mount as the installation component of MDOF DVA can reduce the static deflection from $0.337 \mathrm{~m}$ to $0.03 \mathrm{~m}$, with a reduction of $91 \%$.

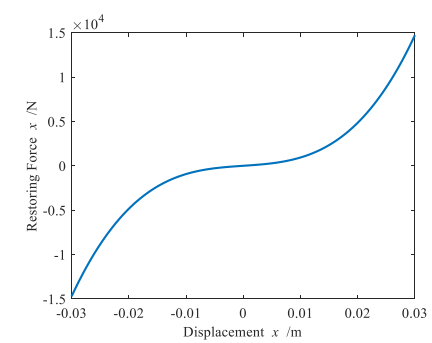

(a) Force-displacement

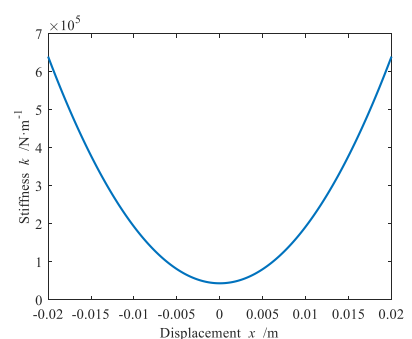

(b) Stiffness-displacement

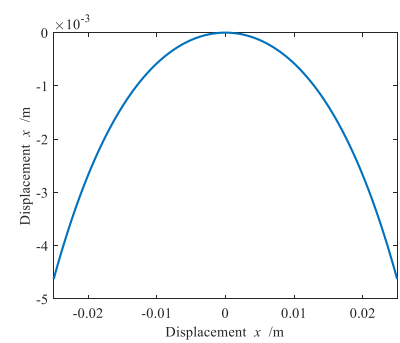

(c) roller guide curve

Fig. 9. Force, Stiffness, roller guide curve of the HSLDS mount.

\section{Simulation experiment}

In section 3, the mounting component of the MDOF DVA is linear elastic spring. In order to verify the vibration absorption performance of the MDOF DVA when the installation components are HSLDS mounts, a nonlinear simulation experiment is applied in this section.

A nonlinear time domain high-speed train model is established by MATLAB/SIMULINK software based on Fig. 4. Using the object-oriented modeling method, the vehicle dynamics system components can be divided into four categories[16]: (1) Structure; (2) Suspension; (3) Wheel- 
rail contact; (4) Track input. Structure category includes one carbody, one MDOF DVA, two bogies and four wheelsets. Suspension category is eight primary suspensions, four secondary suspensions and four springs for MDOF DVA. Wheel-rail contact category considers the linear wheel-rail contact relationship. Track input is time domain spectrum which is translated according to the PSD of high-speed track irregularity. The nonlinear force characteristics of the HSLDS mount is built in the simulation model by interpreted function.

The Sperling indices [18] of the carbody with and without MDOF DVA are shown in Fig. 10 at different operating speeds. It can be seen from the figure that the vertical and lateral Sperling indices at carbody middle and above trailing bogie have certain improvements after MDOF DVA is applied. Comparing the calculation results of the carbody with MDOF DVA installed by HSLDS mounts and without DVA at the speed of $350 \mathrm{~km} / \mathrm{h}$, the vertical Sperling index at carbody middle and above the trailing bogie decreased by $0.16,0.11$, respectively, and the lateral Sperling index at the same positions deceased by $0.26,0.10$, respectively. The vertical and lateral Sperling indexes of carbody above trailing bogie exceeds 2.5 when the operating speeds are over $250 \mathrm{~km} / \mathrm{h}$, which is not acceptable for the operation of high-speed trains. By the application of MDOF DVA, the Sperling indices at this position is reduced to below 2.5 , which means that the ride quality level is excellent.

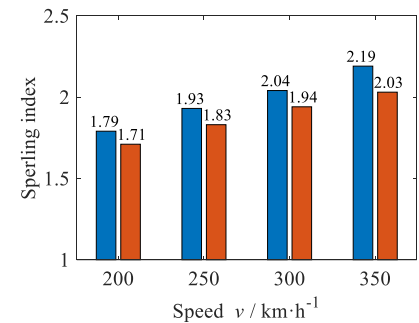

(a) Vertical Sperling Indexes of carbody middle

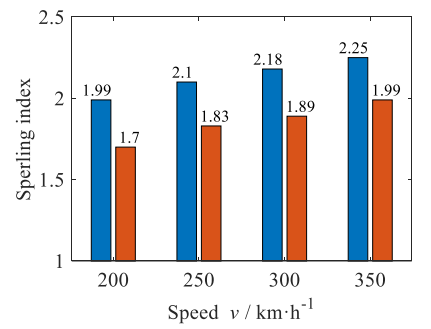

(d) Lateral Sperling Indexes of carbody middle

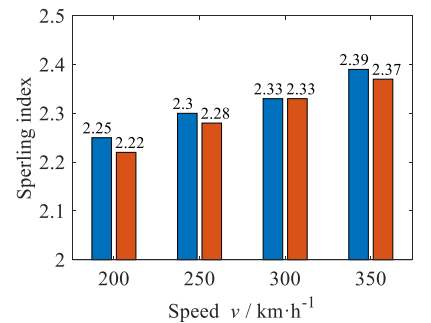

(b) Vertical Sperling Indexes of carbody above leading bogie

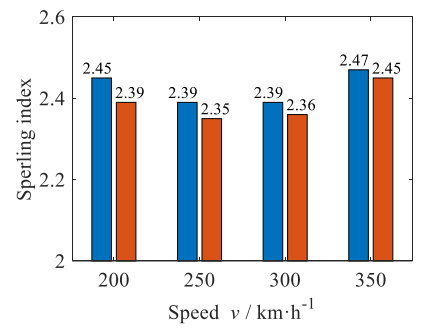

(e) Lateral Sperling Indexes of carbody above leading bogie

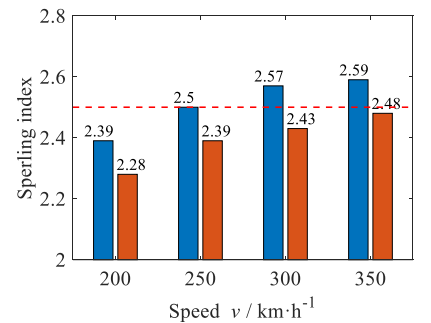

(c) Vertical Sperling Indexes of carbody above trailing bogie

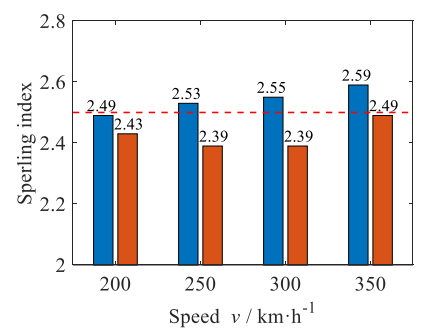

(f) Lateral Sperling Indexes of carbody above trailing bogie

Fig. 10 Sperling indexes of different connection method ( $\square$-With MDOF DVA; $\square$-Without DVA)

The acceleration RMS of each DOF of the carbody with and without MDOF DVA are shown in Fig. 11 at different operating speeds. It can be seen from the figures that the vibrations of all DOFs of the carbody are suppressed by MDOF DVA. Among these, the vibration suppression performance on lateral motion is the best, the acceleration RMS of which are reduced by $39 \%, 34 \%$, $38 \%, 33 \%$ at the operation speeds of $200,250,300,350 \mathrm{~km} / \mathrm{h}$, respectively. When the operating speed is $350 \mathrm{~km} / \mathrm{h}$, the vibration acceleration RMS of bouncing, rolling, pitching and yawing reduced by $15 \%, 34 \%, 6 \%$, and $5 \%$, respectively. 


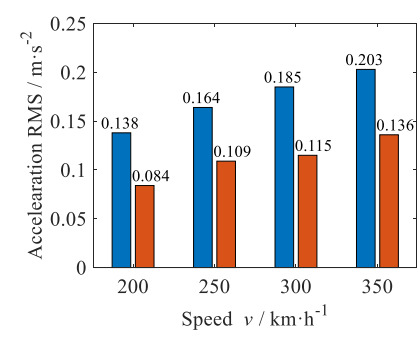

(a) lateral motion

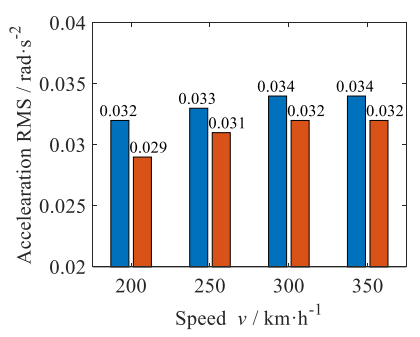

(d) pitching

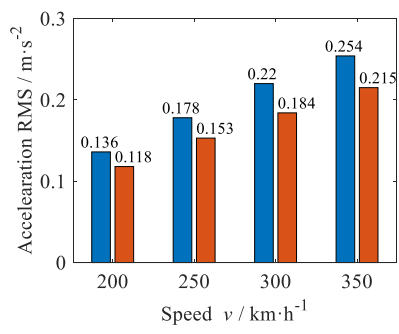

(b) bouncing

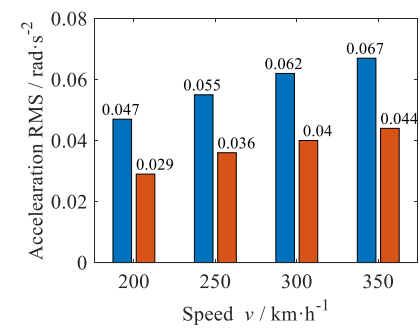

(c) rolling

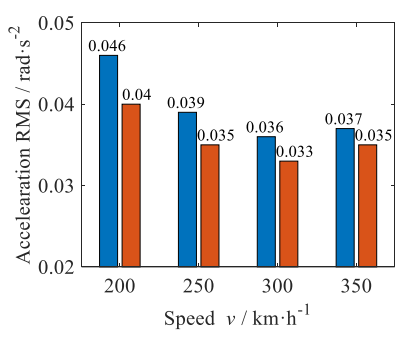

(e) yawing

Fig. 11 Acceleration RMS values of different connection method. ( $\square$-With MDOF DVA; $\square$-Without DVA)

Summarizing Fig. 10 and Fig. 11, it can be found that the MDOF DVA installed under the carbody by using HSLDS mounts can simultaneously achieve dynamic vibration absorption of the carbody in five degrees of freedom. Affected by the limitation of parameters and the coupled vibration, the vibration absorption performance of lateral motion, bouncing and rolling have a significant effect, while pitching and yawing are not very obvious. The vibration of the carbody is suppressed and the ride quality is improved when the MDOF DVA is applied on a high-speed train.

\section{Conclusions}

In this paper, a MDOF DVA is proposed to suppress the rigidity vibration of high-speed trains. The main conclusions are shown as follow.

(1) A 12-DOF of two objects is established, and the vibration absorption mechanism of the MDOF DVA is introduced. By combining the design method of classical single DVA and genetic algorithm, it found that the MDOF DVA can absorb the longitudinal motion, bouncing, rolling, pitching and yawing vibrations of main system simultaneously.

(2) A high-speed train dynamic model is established, and a MDOF DVA that absorbs the different vibrations simultaneously is designed. With the MDOF DVA, the lateral motion, bouncing and pitching can achieve the best vibration absorption performance at the same time. For the installation of MDOF DVA with the low vertical dynamic stiffness, an HSLDS mount is designed based on a cam-roller-spring mechanism. Compared with the linear elastic spring, the equipment can obtain the extremely low static deflection with a drop of $91 \%$ and even the same dynamic stiffness near the equilibrium position.

(3) A high-speed train dynamic model with the consideration of the nonlinearity of the stiffness of the installed components is established. By using time integration simulation experiment, the vibration suppression performance of the MDOF DVA with the installation of HSLDS mount is verified. The results show that MDOF DVA can effectively absorb the rigid vibration of the carbody, and improve the ride quality of the high-speed train. 


\section{Acknowledgements}

Not applicable.

\section{Authors' contributions}

Yu Sun was in charge of the whole research and wrote the manuscript; Jinsong Zhou discussed and read the manuscript; Dao Gong and Yuanjin Ji assisted with the analysis and validation. All authors read and approved the final manuscript.

\section{Authors' Information}

Yu Sun, born in 1991, is currently a post doctor in Postdoctoral Station of Mechanical Engineering, Tongji University. He received his Ph.D in Vehicle Operation Engineering from Tongji University. His research interests include railway vehicle dynamics and vibration control.

Jinsong Zhou, born in 1969, is currently a Professor in Institute of Rail and Transit, Tongji University. He received his Ph.D in Mechanical Engineering from Shanghai Jiaotong Uni-versity. He has been researching on railway vehicle dy-namics, modal parameter testing and control of vibration and sound of railway vehicles.

Dao Gong, born in 1985, is currently an Associate Professor in Institute of Rail and Transit, Tongji University. He received his Ph.D in Vehicle Operation Engineering from Tongji University. He has been researching on railway vehicle vibration testing and control.

Yuanjin Ji, born in 1989, is currently a post doctor in Postdoctoral Station of Mechanical Engineering, Tongji University. He received his Ph.D in Vehicle Operation Engineering from Tongji University. His research focus on wheel-rail contact.

\section{Funding}

This work is supported by National Natural Science Foundation of China (grant no. 51805373), Postdoctoral Innovation Talent Support Program (grant no. BX20200240), China Postdoctoral Science Foundation (grant no. 2020M671207).

\section{Competing interests}

No potential conflict of interest was reported by the authors.

\section{References}

[1] Thompson DJ. A continuous damped vibration absorber to reduce broad-band wave propagation in beams. J Sound Vib, 2008, 311(3-5):824-842.

[2] Ren MZ. A variant design of the dynamic vibration absorber. J Sound Vib. 2001;245(4):762770.

[3] Seto K. Dynamic Vibratin Absorber and its Applications. Beijin: Machine Press, 2013.

[4] Gong D, Zhou JS, Sun WJ, et al. On the resonant vibration of a flexible railway car body and its suppression with a dynamic vibration absorber. J Vib Control, 2013,19(5):649-657. 
[5] Gong D, Zhou JS, Sun WJ, et al. Method of multi-mode vibration control for the carbody of high-speed electric multiple unit trains. J Sound Vib, 2017,409:94-111.

[6] Tomioka T, Takigami T. Reduction of bending vibration in railway vehicle carbodies using carbody-bogie dynamic interaction, Veh Syst Dyn, 2010,48(sus1):467-486.

[7] Shi HL, Luo R, Wu P, et al. Application of DVA theory in vibration reduction of carbody with suspended equipment for high-speed EMU. Sci China Tech Sci, 2014,57(7): 1425-1438.

[8] Alabuzhewv P, Gritchin A, Kim L, et al. Vibration protecting and measuring systems with quasi-zero stiffness. Taylor \& Francis Group, New York,1989.

[9] Carrella A, Brennan MJ, Waters TP, et al. Force and displacement transmissibility of a nonlinear isolator with high-static-low-dynamic-stiffness. Int J Mech Sci, 2012,55:22-29.

[10] Meng LS, Sun JG, Wu WJ. Theoretical Design and Characteristics Analysis of a Quasi-Zero Stiffness Isolator Using a Disk Spring as Negative Stiffness Element. Shock Vib,2015,1-19.

[11] Zhou JX, Wang XL, Xu DL, et al. Nonlinear dynamic characteristics of a quasi-zero stiffness vibration isolator with cam-roller-spring mechanisms. J Sound Vib, 2015,346:53-69.

[12] Danh LT, Ahn KK. Active pneumatic vibration isolation system using negative stiffness structures for a vehicle seat. J Sound Vib, 2014,333:1245-1268.

[13] Lee CM, Goverdovskiy VN, Sim CS, et al. Ride comfort of a high-speed train through the structural upgrade of a bogie suspension. J Sound Vib, 2016,361:99-107.

[14] Sun Y, Zhou JS, Gong D, et al. Vibration control of high-speed trains self-excitation underchassis equipment by HSLDS vibration isolators. J Mech Sci Technol, 2019,33:65-76.

[15] Sun Y, Gong D, Zhou JS, et al. Low frequency vibration control of railway vehicles based on a high static low dynamic stiffness dynamic vibration absorber. Sci China Tech Sci, 2019,62: 60-69.

[16] Zhou JS. Vibration and control in railway vehicles. Beijing: China Railway Publishing House; 2012.

[17] Xia ZH, Zhou JS, Gong D, et al. On the modal damping abnormal variation mechanism for railway vehicles. Mech Syst Signal Pr, 2019,122: 256-272.

[18] Deng CX, Zhou JS, D. Thompson, et al. Analysis of the consistency of the Sperling index for rail vehicles based on different algorithms, Veh Syst Dyn, 2019. DOI: $10.1080 / 00423114.2019 .1677923$

\section{Appendix A}

Table A1

Parameters for the multi-DOF DVA.

\begin{tabular}{cccc}
\hline Symbols & Meanings & Values & Units \\
\hline$m_{1}$ & Main system mass & 5000 & $\mathrm{~kg}$ \\
$I_{1 x}$ & Main system rolling inertia & 300 & $\mathrm{~kg} \cdot \mathrm{m}^{2}$ \\
$I_{1 y}$ & Main system pitching inertia & 400 & $\mathrm{~kg} \cdot \mathrm{m}^{2}$ \\
$I_{1 z}$ & Main system yawing inertia & 500 & $\mathrm{~kg} \cdot \mathrm{m}^{2}$ \\
$m_{2}$ & Assist system mass & 500 & $\mathrm{~kg}$ \\
$I_{2 x}$ & Assist system rolling inertia & 100 & $\mathrm{~kg} \cdot \mathrm{m}^{2}$ \\
$I_{2 y}$ & Assist system pitching inertia & 150 & $\mathrm{~kg} \cdot \mathrm{m}^{2}$ \\
$I_{2 z}$ & Assist system yawing inertia & 200 & $\mathrm{~kg} \cdot \mathrm{m}^{2}$ \\
$k_{1 x}$ & Longitudinal stiffness of main system & $3.99 \times 10^{6}$ & $\mathrm{kN} / \mathrm{m}$ \\
$k_{1 y}$ & Lateral stiffness of main system & $5.91 \times 10^{6}$ & $\mathrm{kN} / \mathrm{m}$
\end{tabular}




\begin{tabular}{|c|c|c|c|}
\hline$k_{1 z}$ & Vertical stiffness of main system & $4.93 \times 10^{6}$ & $\mathrm{kN} / \mathrm{m}$ \\
\hline$c_{1 x}$ & Longitudinal damping of main system & 16900 & $\mathrm{kN} \cdot \mathrm{s} / \mathrm{m}$ \\
\hline$c_{1 y}$ & Lateral damping of main system & 20700 & $\mathrm{kN} \cdot \mathrm{s} / \mathrm{m}$ \\
\hline$c_{1 z}$ & Vertical damping of main system & 18800 & $\mathrm{kN} \cdot \mathrm{s} / \mathrm{m}$ \\
\hline$k_{2 x}$ & Longitudinal stiffness of assist system & $3.75 \times 10^{6}$ & $\mathrm{kN} / \mathrm{m}$ \\
\hline$k_{2 y}$ & Lateral stiffness of assist system & $2.01 \times 10^{5}$ & $\mathrm{kN} / \mathrm{m}$ \\
\hline$k_{2 z}$ & Vertical stiffness of assist system & $4.02 \times 10^{5}$ & $\mathrm{kN} / \mathrm{m}$ \\
\hline$c_{2 x}$ & Longitudinal damping of assist system & 5200 & $\mathrm{kN} \cdot \mathrm{s} / \mathrm{m}$ \\
\hline$c_{2 y}$ & Lateral damping of assist system & 1200 & $\mathrm{kN} \cdot \mathrm{s} / \mathrm{m}$ \\
\hline$c_{2 z}$ & Vertical damping of assist system & 1700 & $\mathrm{kN} \cdot \mathrm{s} / \mathrm{m}$ \\
\hline$h_{1}$ & Center of gravity of main system & 0.05 & $\mathrm{~m}$ \\
\hline$h_{2}$ & $\begin{array}{l}\text { Vertical distances between gravity center of main system } \\
\text { and assist installation point }\end{array}$ & 0.04 & $\mathrm{~m}$ \\
\hline$h_{3}$ & $\begin{array}{l}\text { Vertical distances between gravity center of assist system } \\
\text { and installation point }\end{array}$ & 0.03 & $\mathrm{~m}$ \\
\hline$a$ & $\begin{array}{l}\text { Half of longitudinal distance of main system installation } \\
\text { point }\end{array}$ & 0.4 & $\mathrm{~m}$ \\
\hline$b$ & Half of lateral distance of main system installation point & 0.3 & $\mathrm{~m}$ \\
\hline$c$ & $\begin{array}{l}\text { Half of longitudinal distance of assist system installation } \\
\text { point }\end{array}$ & 0.2 & $\mathrm{~m}$ \\
\hline$d$ & Half of lateral distance of assist system installation point & 0.2 & $\mathrm{~m}$ \\
\hline
\end{tabular}

Table A2

Parameters for the high-speed train dynamic model.

\begin{tabular}{|c|c|c|c|}
\hline Symbols & Meanings & Values & Units \\
\hline$m_{c}$ & Carbody mass & 38000 & $\mathrm{~kg}$ \\
\hline$J_{c x}$ & Carbody rolling inertia & $1.2 \times 10^{5}$ & $\mathrm{~kg} \cdot \mathrm{m}^{2}$ \\
\hline$J_{c y}$ & Carbody pitching inertia & $1.65 \times 10^{6}$ & $\mathrm{~kg} \cdot \mathrm{m}^{2}$ \\
\hline$J_{c z}$ & Carbody yawing inertia & $1.6 \times 10^{6}$ & $\mathrm{~kg} \cdot \mathrm{m}^{2}$ \\
\hline$m_{f}$ & Frame mass & 2200 & $\mathrm{~kg}$ \\
\hline$J_{f x}$ & Frame rolling inertia & 1240 & $\mathrm{~kg} \cdot \mathrm{m}^{2}$ \\
\hline$J_{f y}$ & Frame pitching inertia & 1230 & $\mathrm{~kg} \cdot \mathrm{m}^{2}$ \\
\hline$J_{f z}$ & Frame yawing inertia & 2340 & $\mathrm{~kg} \cdot \mathrm{m}^{2}$ \\
\hline$m_{e}$ & DVA mass & 6000 & $\mathrm{~kg}$ \\
\hline$J_{e x}$ & DVA rolling inertia & 40000 & $\mathrm{~kg} \cdot \mathrm{m}^{2}$ \\
\hline$J_{e y}$ & DVA pitching inertia & 65000 & $\mathrm{~kg} \cdot \mathrm{m}^{2}$ \\
\hline$J_{e z}$ & DVA yawing inertia & 65000 & $\mathrm{~kg} \cdot \mathrm{m}^{2}$ \\
\hline$m_{w}$ & Wheelset mass & 1520 & $\mathrm{~kg}$ \\
\hline$J_{w z}$ & Wheelset yawing inertia & 693 & $\mathrm{~kg} \cdot \mathrm{m}^{2}$ \\
\hline$k_{s x}$ & Longitudinal stiffness of secondary suspension & $3 \times 10^{5}$ & $\mathrm{kN} / \mathrm{m}$ \\
\hline$c_{s x}$ & Longitudinal damping of secondary suspension & 70000 & $\mathrm{~N} \cdot \mathrm{s} / \mathrm{m}$ \\
\hline$k_{s y}$ & Lateral stiffness of secondary suspension & $3 \times 10^{5}$ & $\mathrm{kN} / \mathrm{m}$ \\
\hline$c_{s y}$ & Lateral damping of secondary suspension & 5000 & $\mathrm{~N} \cdot \mathrm{s} / \mathrm{m}$ \\
\hline$k_{s z}$ & Vertical stiffness of secondary suspension & $4 \times 10^{5}$ & $\mathrm{kN} / \mathrm{m}$ \\
\hline$c_{s z}$ & Vertical damping of secondary suspension & 10000 & $\mathrm{~N} \cdot \mathrm{s} / \mathrm{m}$ \\
\hline$k_{e x}$ & Longitudinal stiffness of DVA suspension & 46900 & $\mathrm{kN} / \mathrm{m}$ \\
\hline$c_{e x}$ & Longitudinal damping of DVA suspension & 2010 & $\mathrm{~N} \cdot \mathrm{s} / \mathrm{m}$ \\
\hline$k_{e y}$ & Lateral stiffness of DVA suspension & 52600 & $\mathrm{kN} / \mathrm{m}$ \\
\hline$c_{e y}$ & Lateral damping of DVA suspension & 2130 & $\mathrm{~N} \cdot \mathrm{s} / \mathrm{m}$ \\
\hline$k_{e z}$ & Vertical stiffness of DVA suspension & 46900 & $\mathrm{kN} / \mathrm{m}$ \\
\hline
\end{tabular}




\begin{tabular}{cccc}
$c_{e z}$ & Vertical damping of DVA suspension & 2010 & $\mathrm{~N} \cdot \mathrm{s} / \mathrm{m}$ \\
$k_{p x}$ & Longitudinal stiffness of primary suspension & $1.5 \times 10^{7}$ & $\mathrm{kN} / \mathrm{m}$ \\
$k_{p y}$ & Lateral stiffness of primary suspension & $6.25 \times 10^{6}$ & $\mathrm{kN} / \mathrm{m}$ \\
$k_{p z}$ & Vertical stiffness of primary suspension & $1.28 \times 10^{6}$ & $\mathrm{kN} / \mathrm{m}$ \\
$c_{p z}$ & Vertical damping of primary suspension & 10000 & $\mathrm{~N} \cdot \mathrm{s} / \mathrm{m}$ \\
$h_{\mathrm{df}}$ & Half of bogie distance & 8.7 & $\mathrm{~m}$ \\
$h_{\mathrm{da}}$ & Half of axle distance & 1.25 & $\mathrm{~m}$ \\
$h_{\mathrm{dp}}$ & Half of primary suspension lateral distance & 1 & $\mathrm{~m}$ \\
$h_{\mathrm{ds}}$ & Half of secondary suspension lateral distance & 0.95 & $\mathrm{~m}$ \\
$r_{0}$ & Radius wheel & 0.46 & $\mathrm{~m}$ \\
$\lambda$ & Tread conicity & 0.05 & - \\
$f_{11}$ & Longitudinal creep coefficients & $1.2 \times 10^{7}$ & $\mathrm{~N}$ \\
$f_{22}$ & Lateral creep coefficients & $9.8 \times 10^{6}$ & $\mathrm{~N}$ \\
$h_{s e e}$ & Vertical distance between DVA and its installation point & 0.3 & $\mathrm{~m}$ \\
$h_{s c e}$ & Vertical distance between carbody and DVA installation & 0.65 & $\mathrm{~m}$ \\
Lex & point & 2 & $\mathrm{~m}$ \\
$l e y$ & Half of longitudinal DVA installation point & Velocity & $\mathrm{m}$ \\
$v$ & Half of lateral DVA installation point & 300 & $\mathrm{~km} / \mathrm{h}$ \\
\hline
\end{tabular}

\section{Appendix B}

The equations of motion for the first wheelset, first bogie frame, carbody, and MDOF DVA in the high-speed train dynamic model are written as

$$
\begin{aligned}
& \left\{\begin{array}{l}
m_{w} \ddot{y}_{w 1}+2 k_{p y} y_{w 1}-2 k_{p y} y_{f 1}-2 h_{d a} k_{p y} \psi_{f 1}+2 h_{d a} k_{p y} \psi_{w 1}-2 h_{p s f} k_{p y} \varphi_{f 1}=0 \\
I_{w z} \ddot{\psi}_{w 1}+2\left(h_{d a}^{2} k_{p y}+h_{d p}^{2} k_{p x}\right) \psi_{w 1}-2\left(h_{d a}^{2} k_{p y}+h_{d p}^{2} k_{p x}\right) \psi_{f 1}-2 h_{d a} k_{p y} y_{f 1}+2 h_{d a} k_{p y} y_{w 1}-2 h_{d a} h_{p s f} k_{p y} \varphi_{f 1}=0
\end{array}\right.
\end{aligned}
$$

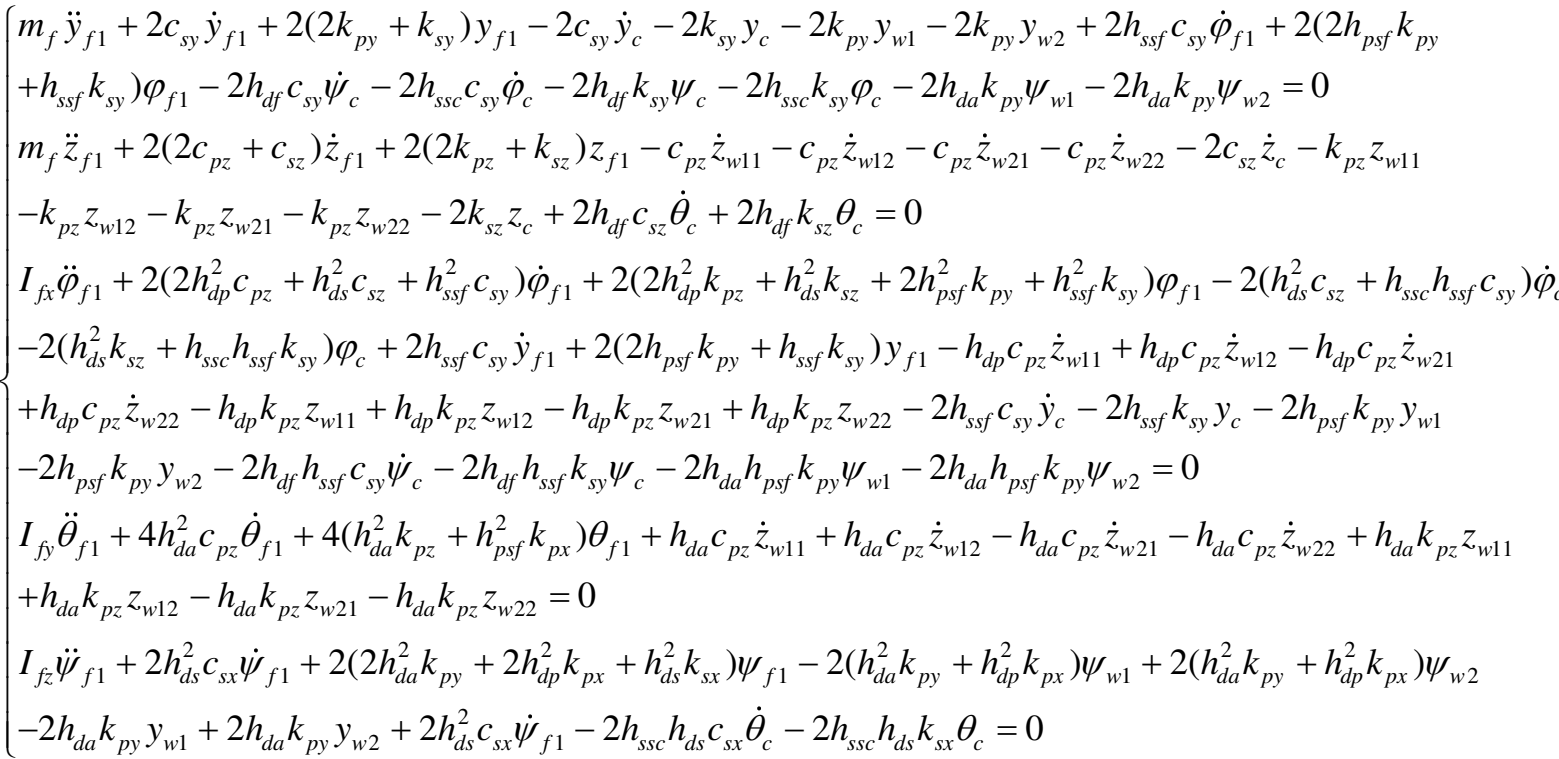




$$
\begin{aligned}
& \left(m_{c} \ddot{y}_{c}+4\left(c_{e y}+c_{s y}\right) \dot{y}_{c}+4\left(k_{e y}+k_{s y}\right) y_{c}-4 c_{e y} \dot{y}_{e}-4 k_{e y} y_{e}-2 c_{s y} \dot{y}_{f 1}-2 c_{s y} \dot{y}_{f 2}-2 k_{s y} y_{f 1}-2 k_{s y} y_{f 2}\right. \\
& +4\left(h_{s s e} c_{e y}+h_{s s c} c_{s y}\right) \dot{\varphi}_{c}+4\left(h_{s s e} k_{e y}+h_{s s c} k_{s y}\right) \varphi_{c}-4 h_{s s e} c_{e y} \dot{\varphi}_{e}-4 h_{s s e} k_{e y} \varphi_{e}-2 h_{s s f} c_{s y} \dot{\varphi}_{1}-2 h_{s s f} c_{s y} \dot{\varphi}_{2} \\
& -2 h_{s s f} k_{s y} \varphi_{1}-2 h_{s s f} k_{s y} \varphi_{2}=0 \\
& m_{c} \ddot{z}_{c}+4\left(c_{e z}+c_{s z}\right) \dot{z}_{c}+4\left(k_{e z}+k_{s z}\right) z_{c}-4 c_{e z} \dot{z}_{e}-2 c_{s z} \dot{z}_{f 1}-2 c_{s z} \dot{z}_{f 2}-4 k_{e z} z_{e}-2 k_{s z} z_{f 1}-2 k_{s z} z_{f 2}=0 \\
& I_{c x} \ddot{\varphi}_{c}+4\left(h_{d e s}^{2} c_{e z}+h_{d s}^{2} c_{s z}+h_{s s e}^{2} c_{e y}+h_{s s c}^{2} c_{s y}\right) \dot{\varphi}_{c}+4\left(h_{d e s}^{2} k_{e z}+h_{d s}^{2} k_{s z}+h_{s s e}^{2} k_{e y}+h_{s s c}^{2} k_{s y}+m_{c} g h_{s s c}\right) \varphi_{c}-4\left(h_{d e s}^{2} c_{e z}\right. \\
& \left.+h_{s s e}^{2} c_{e y}\right) \dot{\varphi}_{e}-2\left(h_{d s}^{2} c_{s z}+h_{s s f} h_{s s c} c_{s y}\right) \dot{\varphi}_{f 1}-2\left(h_{d s}^{2} c_{s z}+h_{s s f} h_{s s c} c_{s y}\right) \dot{\varphi}_{f 2}-4\left(h_{d e s}^{2} k_{e z}+h_{s s e}^{2} k_{e y}\right) \varphi_{e}-2\left(h_{d s}^{2} k_{s z}\right. \\
& \left.+h_{s s f} h_{s s c} k_{s y}\right) \varphi_{f 1}-2\left(h_{d s}^{2} k_{s z}+h_{s s f} h_{s s c} k_{s y}\right) \varphi_{f 2}+4\left(h_{s s e} c_{e y}+h_{s s c} c_{s y}\right) \dot{y}_{c}+4\left(h_{s s e} k_{e y}+h_{s s c} k_{s y}\right) y_{c}-4 h_{s s e} c_{e y} \dot{y}_{e} \\
& -2 h_{s s c} c_{s y} \dot{y}_{f 1}-2 h_{s s c} c_{s y} \dot{y}_{f 2}-4 h_{s s e} k_{e y} y_{e}-2 h_{s s c} k_{s y} y_{f 1}-2 h_{s s c} k_{s y} y_{f 2}=0 \\
& I_{c y} \ddot{\theta}_{c}+4\left(h_{d e}^{2} c_{e z}+h_{d f}^{2} c_{s z}+h_{s s c}^{2} c_{e x}+h_{s s c}^{2} c_{s x}\right) \dot{\theta}_{c}+4\left(h_{d e}^{2} k_{e z}+h_{d f}^{2} k_{s z}+h_{s s c}^{2} k_{e x}+h_{s s c}^{2} k_{s x}\right) \theta_{c}-4\left(h_{d e}^{2} c_{e z}\right. \\
& \left.+h_{s s e} h_{s s c} c_{e x}\right) \dot{\theta}_{e}-4\left(h_{d e}^{2} k_{e z}+h_{s s e} h_{s s c} k_{e x}\right) \theta_{e}+2 h_{d f} c_{s z} \dot{z}_{f 1}-2 h_{d f} c_{s z} \dot{z}_{f 2}+2 h_{d f} k_{s z} z_{f 1}-2 h_{d f} k_{s z} z_{f 2} \\
& -2 h_{d s} h_{s s c} c_{s x} \dot{\psi}_{f 1}+2 h_{d s} h_{s s c} c_{s x} \dot{\psi}_{f 2}-2 h_{d s} h_{s s c} k_{s x} \psi_{f 1}+2 h_{d s} h_{s s c} k_{s x} \psi_{f 2}=0 \\
& I_{c z} \ddot{\psi}_{c}+4\left(h_{d e}^{2} c_{e y}+h_{d e s}^{2} c_{e x}+h_{d f}^{2} c_{s y}+h_{d s}^{2} c_{s x}\right) \dot{\psi}_{c}+4\left(h_{d e}^{2} k_{e y}+h_{d e s}^{2} k_{e x}+h_{d f}^{2} k_{s y}+h_{d s}^{2} k_{s x}\right) \psi_{c}-4\left(h_{d e}^{2} c_{e y}\right. \\
& \left.+h_{d e s}^{2} c_{e x}\right) \dot{\psi}_{e}-4\left(h_{d e}^{2} k_{e y}+h_{d e s}^{2} k_{e x}\right) \psi_{e}-2 h_{d f} c_{s y} \dot{y}_{f 1}+2 h_{d f} c_{s y} \dot{y}_{f 2}-2 h_{d f} k_{s y} y_{f 1}+2 h_{d f} k_{s y} y_{f 2}-2 h_{s s f} h_{d f} c_{s y} \dot{\varphi}_{f 1} \\
& +2 h_{s s f} h_{d f} c_{s y} \dot{\varphi}_{f 2}-2 h_{s s f} h_{d f} k_{s y} \varphi_{f 1}+2 h_{s s f} h_{d f} k_{s y} \varphi_{f 2}=0 \\
& \left\{\begin{array}{l}
m_{e} \ddot{y}_{e}+4 c_{e y} \dot{y}_{e}+4 k_{e y} y_{e}-4 c_{e y} \dot{y}_{c}-4 k_{e y} y_{c}-4 h_{s s e} c_{e y} \dot{\varphi}_{c}+4 h_{s s e} c_{e y} \dot{\varphi}_{e}-4 h_{s s e} k_{e y} \varphi_{c}+4 h_{s s e} k_{e y} \varphi_{e}=0 \\
m_{e} \ddot{z}_{e}+4 c_{e z} \dot{z}_{e}+4 k_{e z} z_{e}-4 c_{e z} \dot{z}_{c}-4 k_{e z} z_{c}=0 \\
I_{e x} \ddot{\varphi}_{e}+4\left(h_{d e s}^{2} c_{e z}+h_{s s e}^{2} c_{e y}\right) \dot{\varphi}_{e}+4\left(h_{d e s}^{2} k_{e z}+h_{s s e}^{2} k_{e y}\right) \varphi_{e}-4\left(h_{d e s}^{2} c_{e z}+h_{s s e}^{2} c_{e y}\right) \dot{\varphi}_{c}-4\left(h_{d e s}^{2} k_{e z}+h_{s s e}^{2} k_{e y}\right) \varphi_{c} \\
-4 h_{s s e} c_{e y} \dot{y}_{c}+4 h_{s s e} c_{e y} \dot{y}_{e}-4 h_{s s e} k_{e y} y_{c}+4 h_{s s e} k_{e y} y_{e}=0 \\
I_{e y} \ddot{\theta}_{e}+4\left(h_{d e}^{2} c_{e z}+h_{s s e}^{2} c_{e x}\right) \dot{\theta}_{e}+4\left(h_{d e}^{2} k_{e z}+h_{s s e}^{2} k_{e x}\right) \theta_{e}-4\left(h_{d e}^{2} c_{e z}+h_{s s c} h_{s s e} c_{e x}\right) \dot{\theta}_{c}-4\left(h_{d e}^{2} k_{e z}+h_{s s c} h_{s s e} k_{e x}\right) \theta_{c}=0 \\
I_{e z} \ddot{\psi}_{e}+4\left(h_{d e}^{2} c_{e y}+h_{d e s}^{2} c_{e x}\right) \dot{\psi}_{e}+4\left(h_{d e}^{2} k_{e y}+h_{d e s}^{2} k_{e x}\right) \psi_{e}-4\left(h_{d e}^{2} c_{e y}+h_{d e s}^{2} c_{e x}\right) \dot{\psi}_{c}-4\left(h_{d e}^{2} k_{e y}+h_{d e s}^{2} k_{e x}\right) \psi_{c}=0
\end{array}\right.
\end{aligned}
$$


Figures

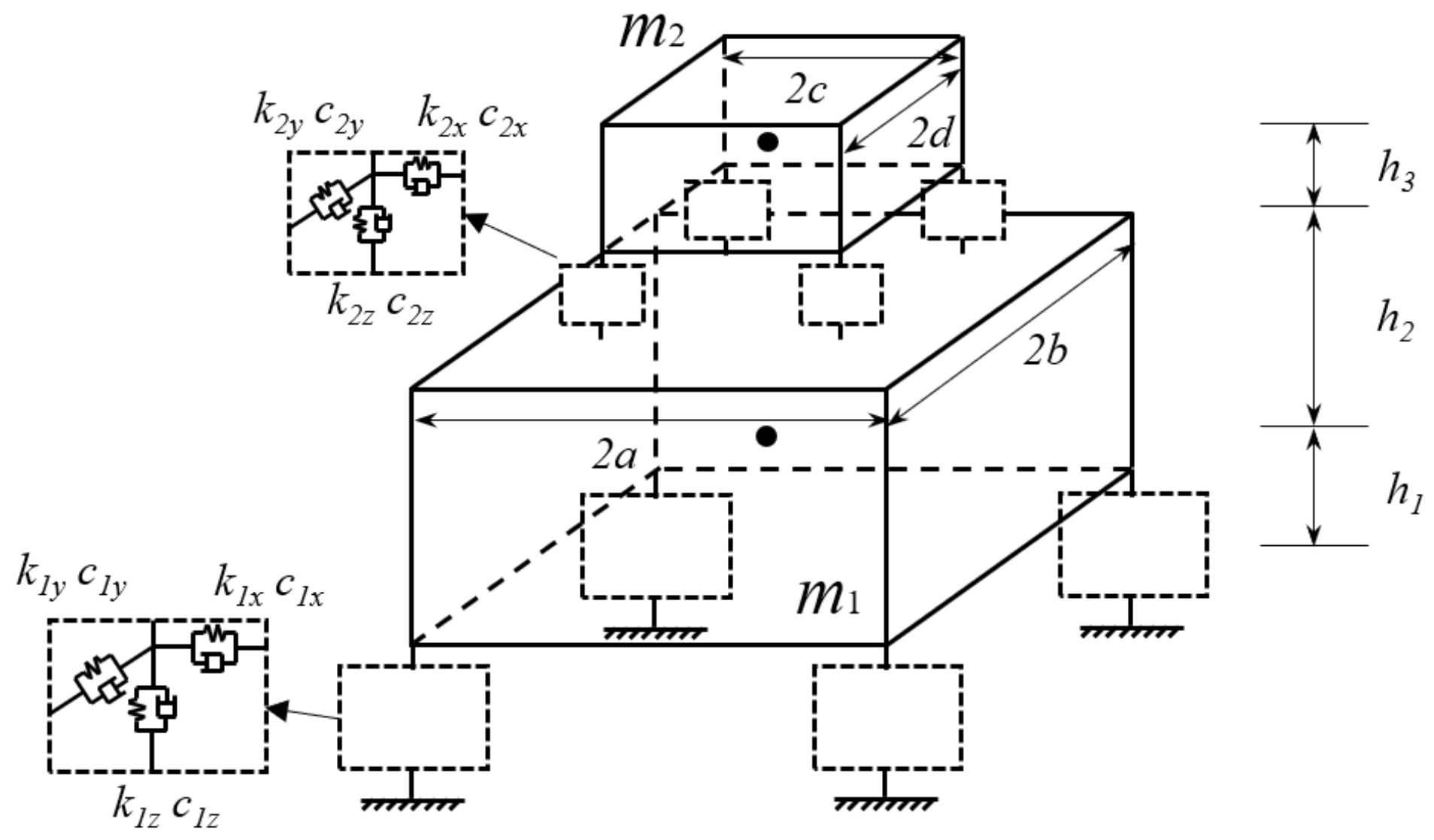

Figure 1

Schematic diagram of a MDOF DVA 


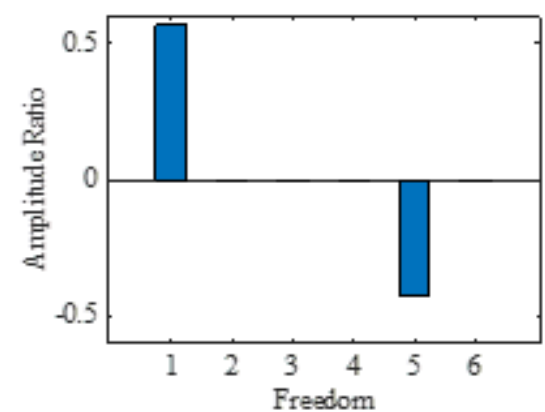

(a) longitudinal motion $(8.60 \mathrm{~Hz})$

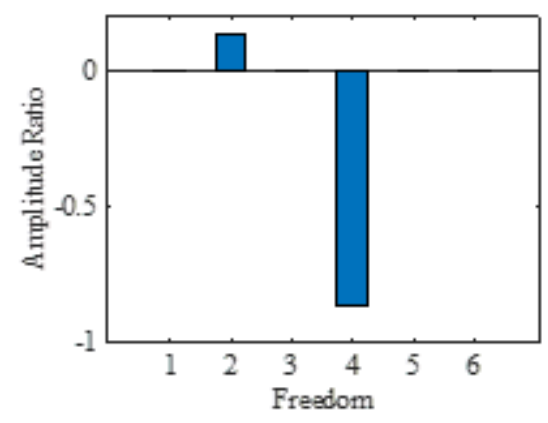

(d) rolling $(14.0 \mathrm{~Hz})$

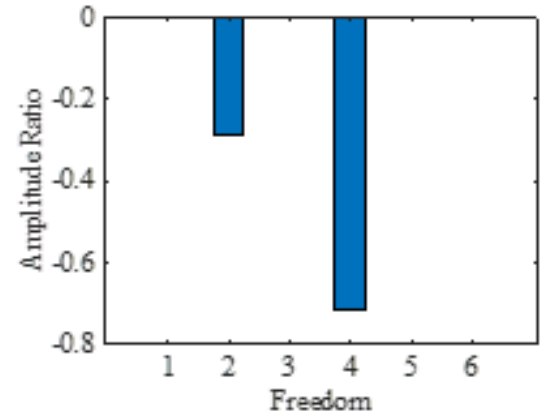

(b) lateral motion $(9.45 \mathrm{~Hz})$

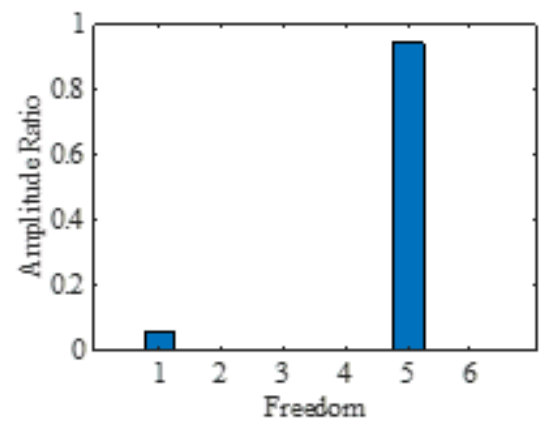

(e) pitching $(14.5 \mathrm{~Hz})$

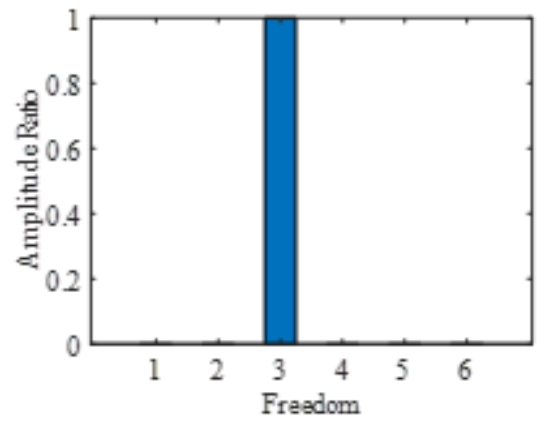

(c) bouncing $(9.93 \mathrm{~Hz})$

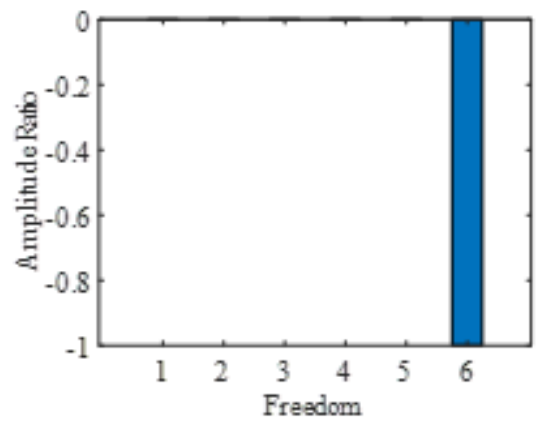

(f) yawing $(16.0 \mathrm{~Hz})$

Figure 2

Vibration shapes of the main system

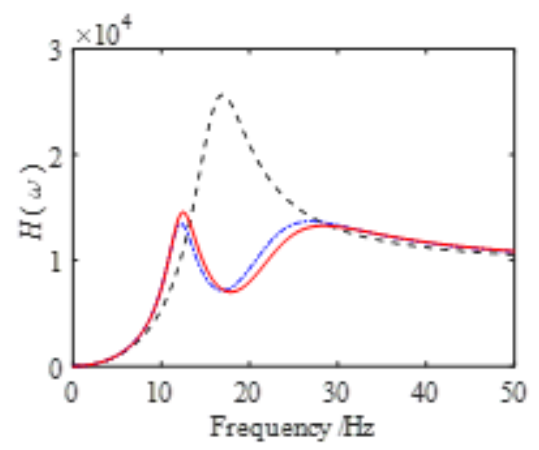

(a) longitudinal motion

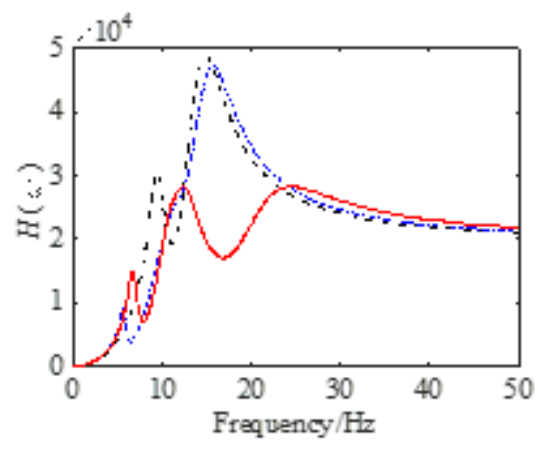

(d) rolling

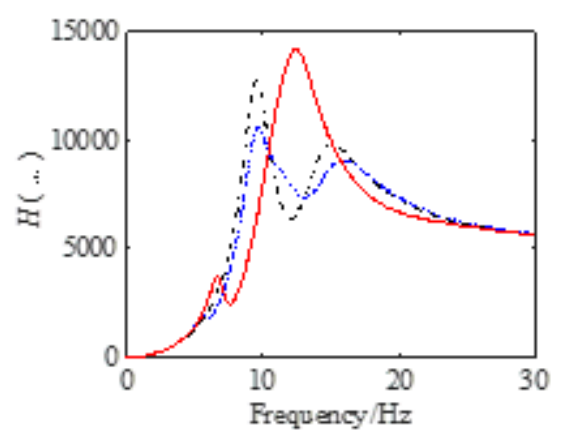

(b) lateral motion

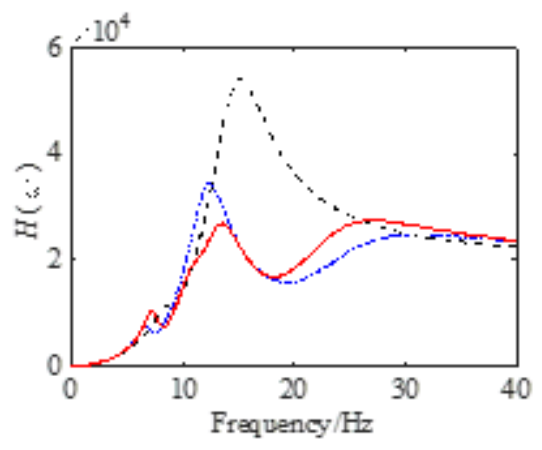

(e) pitching

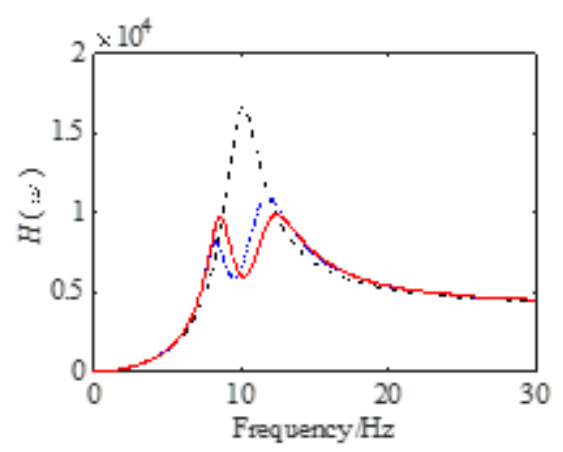

(c) bouncing

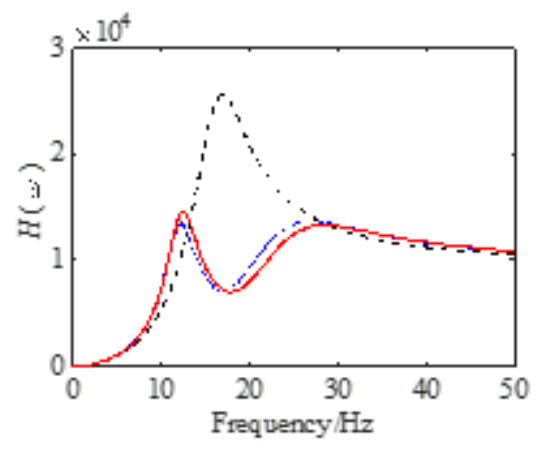

(f) yawing 
Acc RFR of main system. dash line: without MDOF DVA; dash-dot line: with original MDOF DVA; solid line: with optimized MDOF DVA.
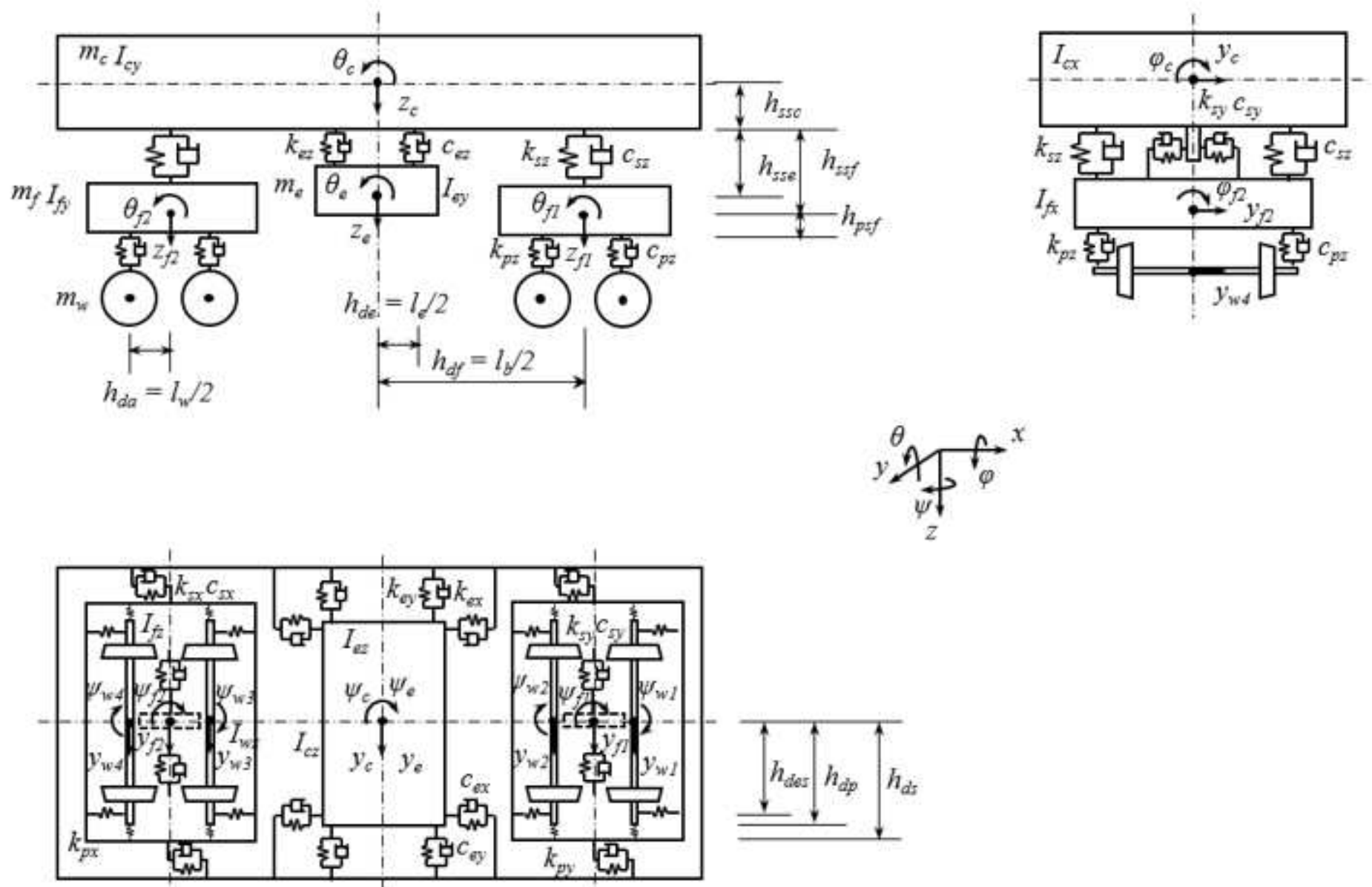

\section{Figure 4}

Dynamic model of the high-speed train 


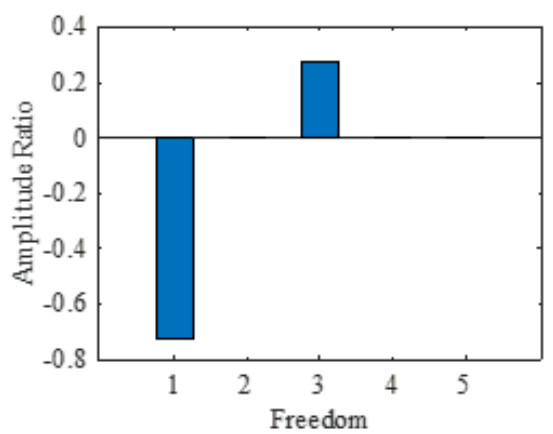

(a) lateral motion $(0.970 \mathrm{~Hz})$

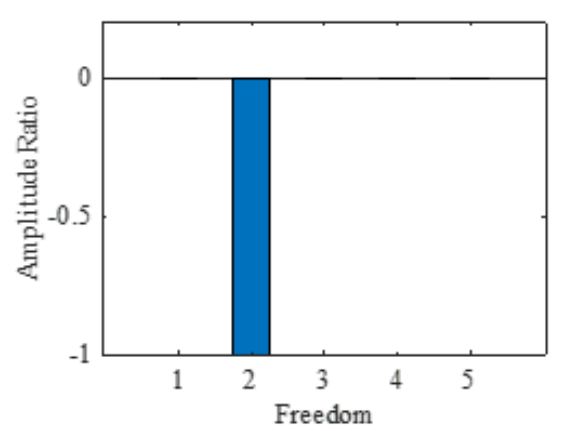

(b) bouncing $(0.958 \mathrm{~Hz})$

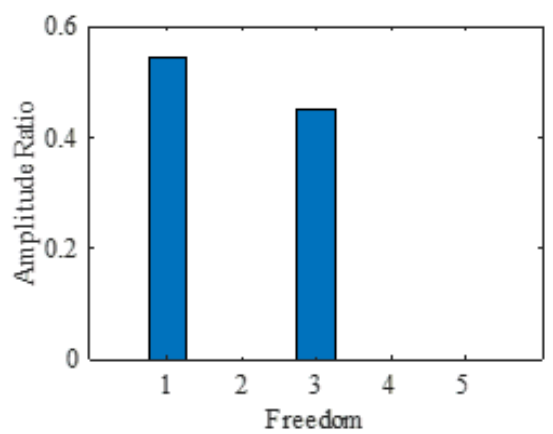

(c) rolling $(0.446 \mathrm{~Hz})$

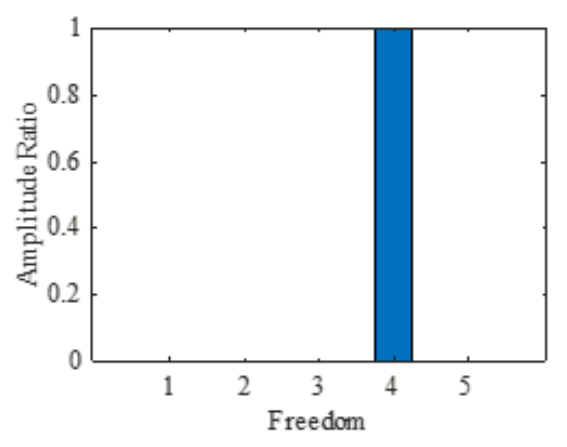

(d) pitching $(1.26 \mathrm{~Hz})$

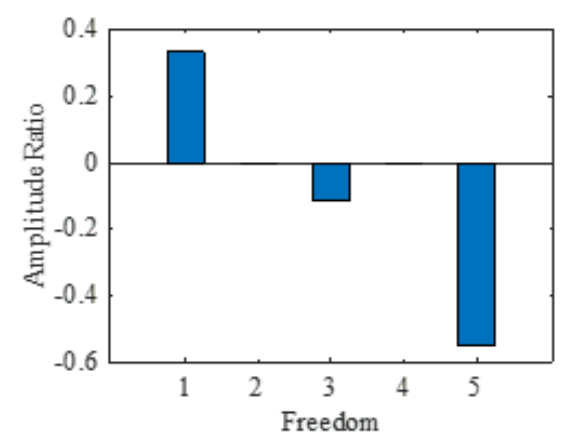

(e) yawing $(1.18 \mathrm{~Hz})$

\section{Figure 5}

Vibration shapes of carbody

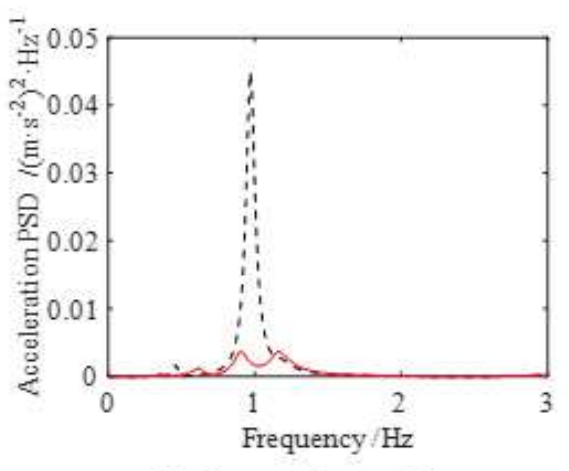

(a) lateral motion

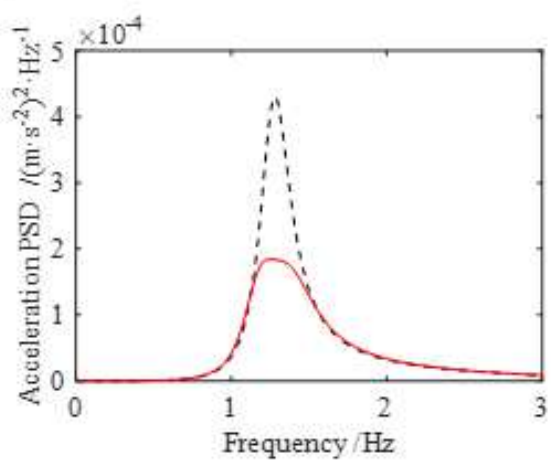

(d) pitching

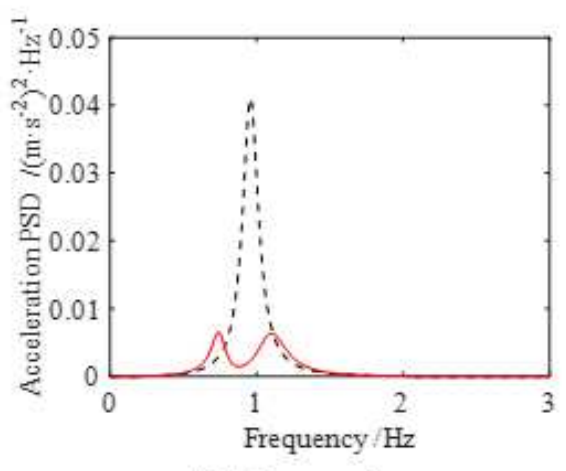

(b) bouncing

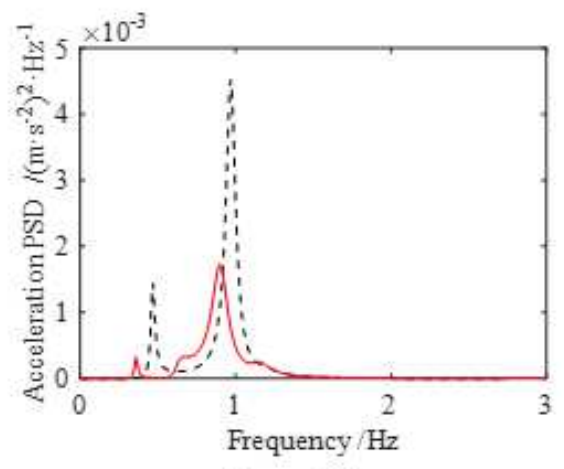

(c) rolling

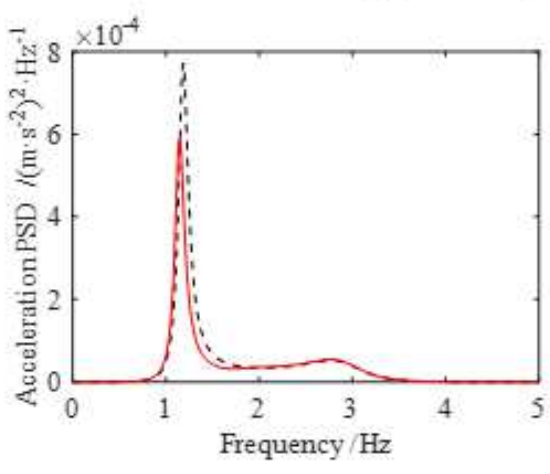

(e) yawing 
PSD of each DOF of the carbody. dash line: without MDOF DVA; solid line: with optimized MDOF DVA.

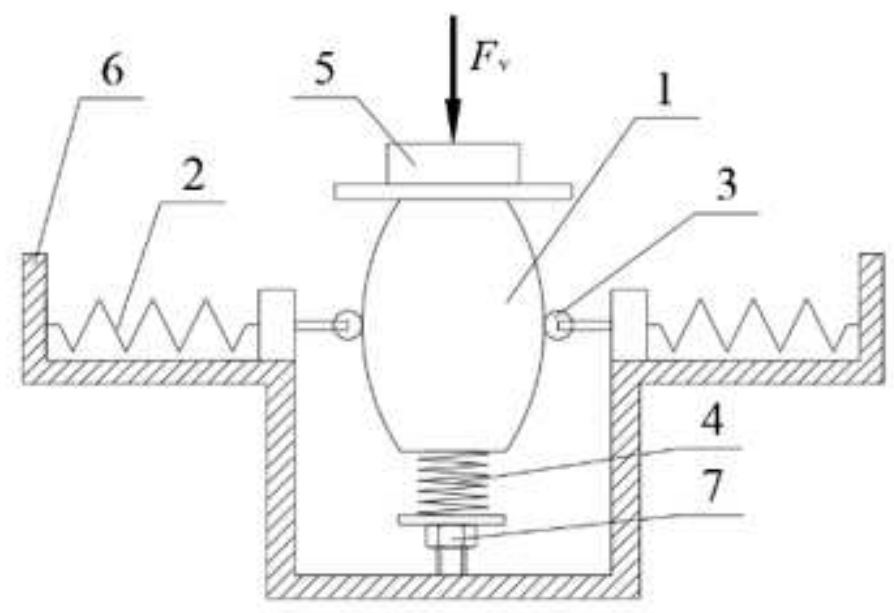

\section{Figure 7}

Schematic design of the HSLDS mount based on target force curve (1-roller guide support, 2- lateral spring, 3-roller, 4-vertical spring, 5- isolated object, 6-fitting seat, 7-height adjuster)

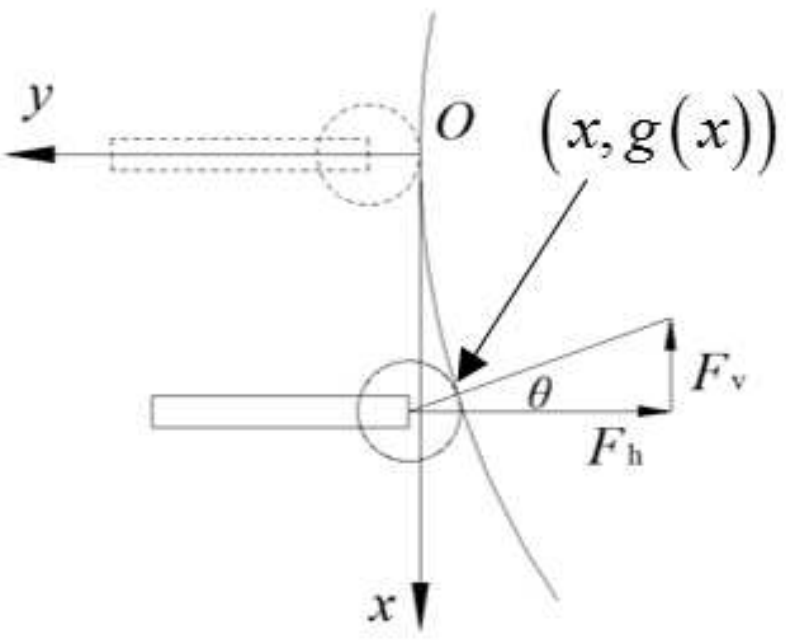

(a) Force schematic (convex)

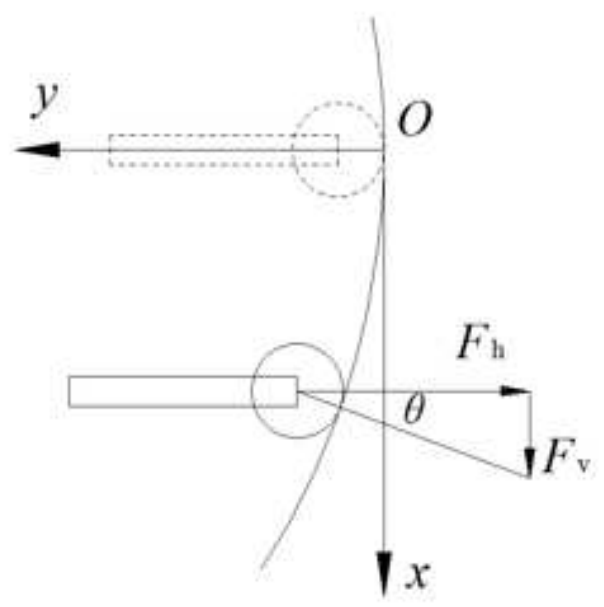

(b) Force schematic (concave)

\section{Figure 8}

Force schematic of the HSLDS mount 


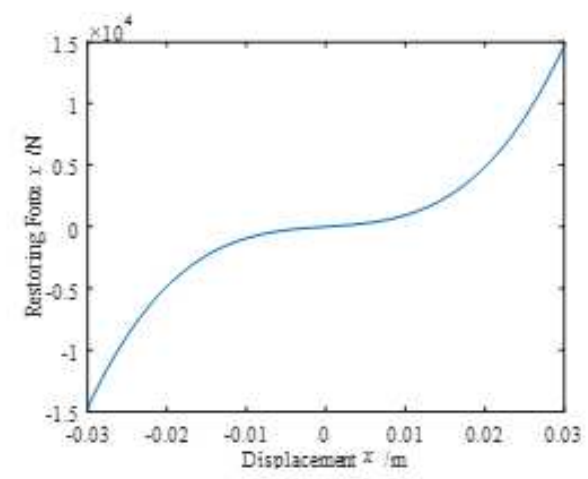

(a) Force-displacement

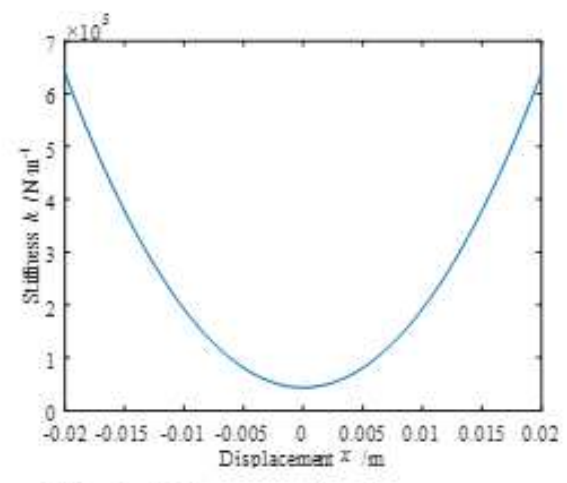

(b) Stiffness-displacement

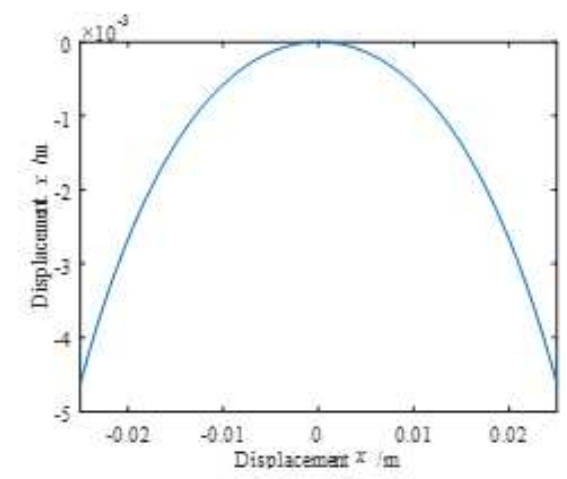

(c) roller guide curve

Figure 9

Force, Stiffness, roller guide curve of the HSLDS mount.

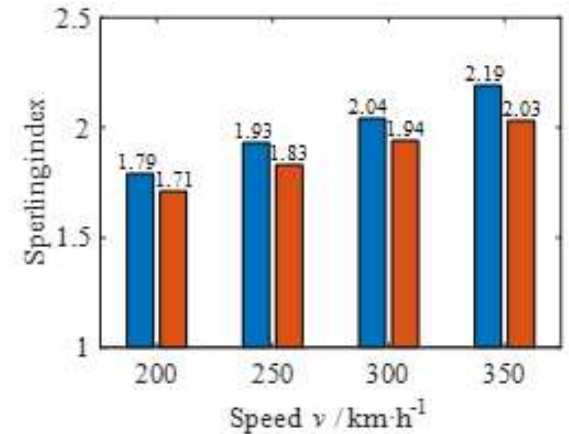

(a) Vertical Sperling Indexes of carbody middle

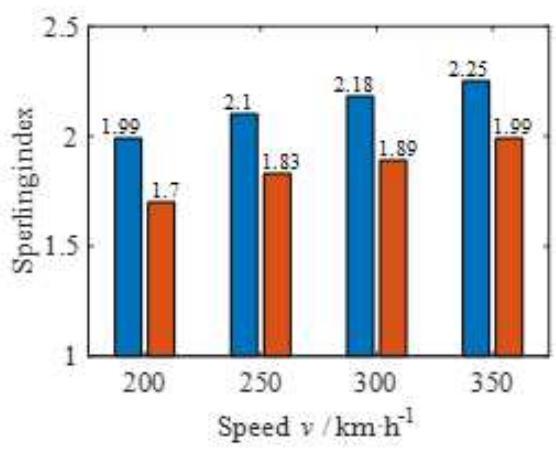

(d) Lateral Sperling Indexes of carbody middle

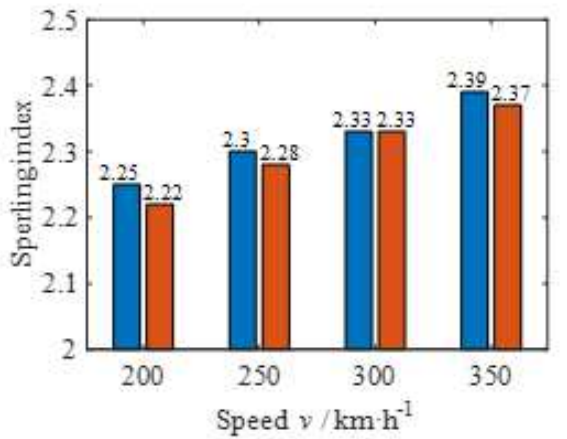

(b) Vertical Sperling Indexes of carbody above leading bogie

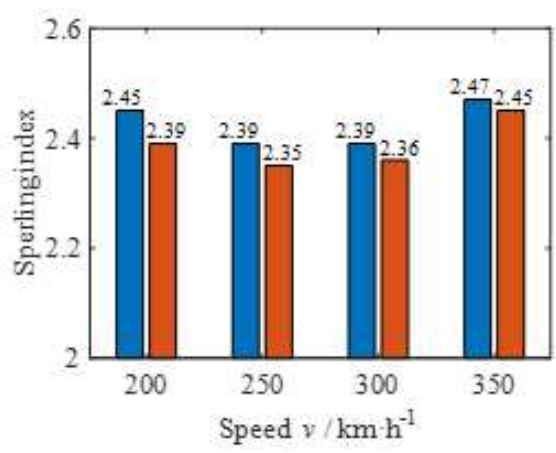

(e) Lateral Sperling Indexes of carbody above leading bogie

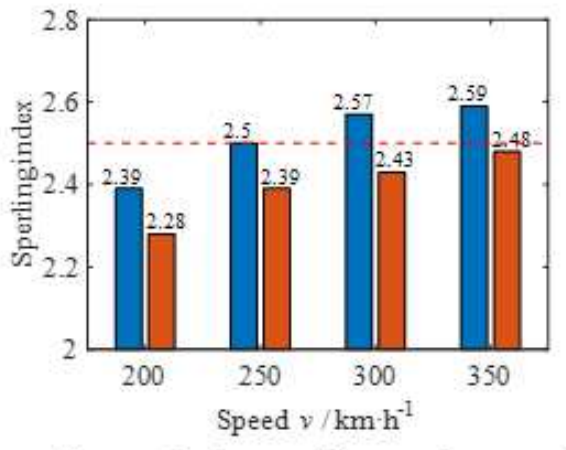

(c) Vertical Sperling Indexes of carbody above trailing bogie

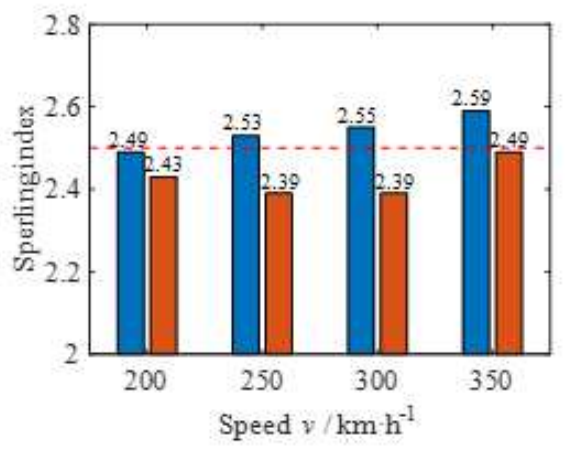

(f) Lateral Sperling Indexes of carbody above trailing bogie

Figure 10

Please see the Manuscript PDF file for the complete figure caption. 


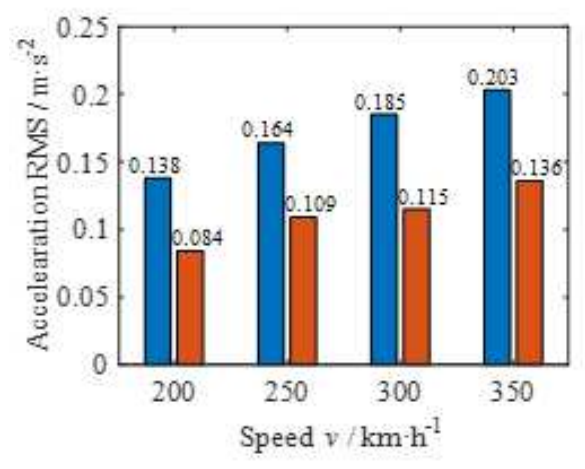

(a) lateral motion

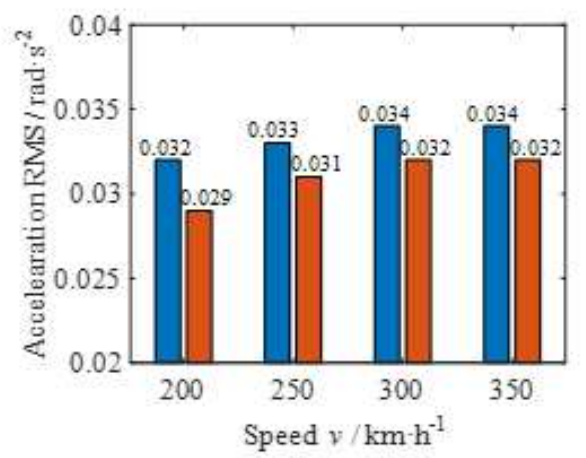

(d) pitching

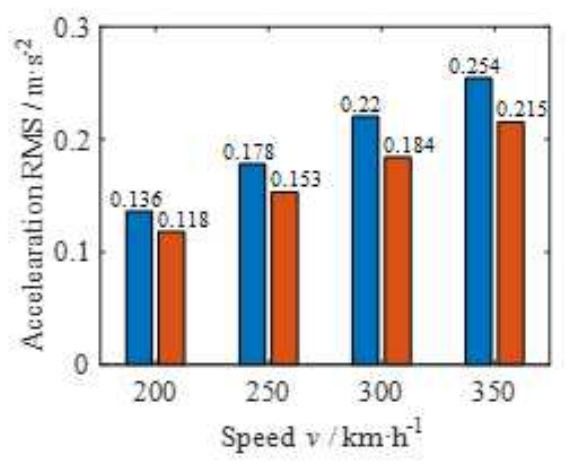

(b) bouncing

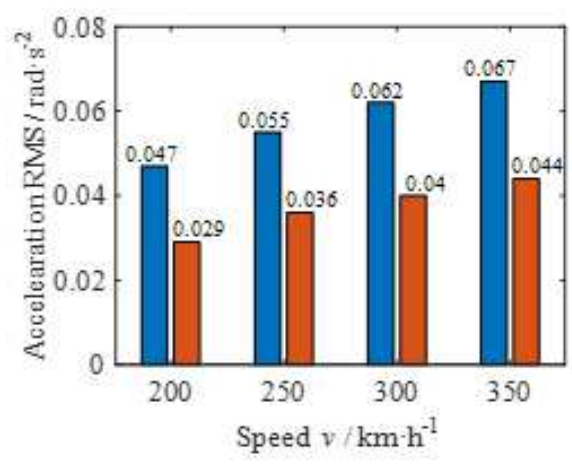

(c) rolling

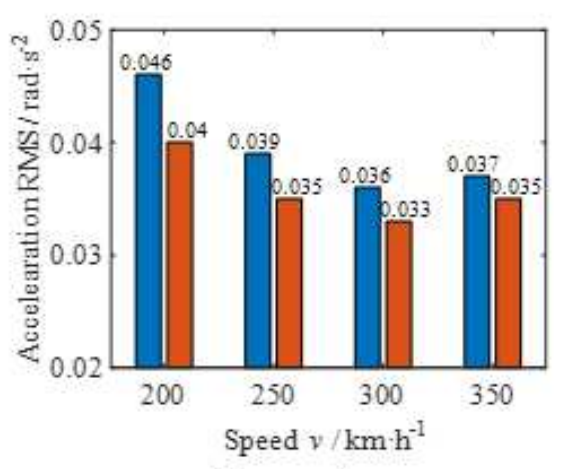

(e) yawing

Figure 11

Please see the Manuscript PDF file for the complete figure caption. 